\title{
The carbon cycle during the Mid Pleistocene Transition: the Southern Ocean Decoupling Hypothesis
}

\author{
P. Köhler ${ }^{1}$ and R. Bintanja ${ }^{2}$ \\ ${ }^{1}$ Alfred Wegener Institute for Polar and Marine Research, PO Box 120161, 27515 Bremerhaven, Germany \\ ${ }^{2}$ KNMI (Royal Netherlands Meteorological Institute), Wilhelminalaan 10, 3732 GK De Bilt, Netherlands
}

Received: 23 June 2008 - Published in Clim. Past Discuss.: 9 July 2008

Revised: 1 October 2008 - Accepted: 7 October 2008 - Published: 2 December 2008

\begin{abstract}
Various hypotheses were proposed within recent years for the interpretation of the Mid Pleistocene Transition (MPT), which occurred during past 2000000 years (2 Myr). We here add to already existing theories on the MPT some data and model-based aspects focusing on the dynamics of the carbon cycle. We find that the average glacial/interglacial (G/IG) amplitudes in benthic $\delta^{13} \mathrm{C}$ derived from sediment cores in the deep Pacific ocean increased across the MPT by $\sim 40 \%$, while similar amplitudes in the global benthic $\delta^{18} \mathrm{O}$ stack LR04 increased by a factor of two over the same time interval. The global carbon cycle box model BICYCLE is used for the interpretation of these observed changes in the carbon cycle. Our simulation approach is based on regression analyses of various paleo-climatic proxies with the LR04 benthic $\delta^{18} \mathrm{O}$ stack over the last $740 \mathrm{kyr}$, which are then used to extrapolate changing climatic boundary conditions over the whole $2 \mathrm{Myr}$ time window. The observed dynamics in benthic $\delta^{13} \mathrm{C}$ cannot be explained if similar relations between LR04 and the individual climate variables are assumed prior and after the MPT. According to our analysis a model-based reconstruction of G/IG amplitudes in deep Pacific $\delta^{13} \mathrm{C}$ before the MPT is possible if we assume a different response to the applied forcings in the Southern Ocean prior and after the MPT. This behaviour is what we call the "Southern Ocean Decoupling Hypothesis". This decoupling might potentially be caused by a different cryosphere/ocean interaction and thus changes in the deep and bottom water formation rates in the Southern Ocean before the MPT, however an understanding from first principles remains elusive. Our hypothesis is also proposing dynamics in atmospheric $p \mathrm{CO}_{2}$ over the past $2 \mathrm{Myr}$. Simulated $p \mathrm{CO}_{2}$ is vary-
\end{abstract}

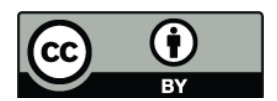

Correspondence to: P. Köhler (peter.koehler@awi.de) ing between 180 and $260 \mu \mathrm{atm}$ before the MPT. The consequence of our Southern Ocean Decoupling Hypothesis is that the slope in the relationship between Southern Ocean SST and atmospheric $p \mathrm{CO}_{2}$ is different before and after the MPT, something for which first indications already exist in the $800 \mathrm{kyr} \mathrm{CO}_{2}$ record from the EPICA Dome $\mathrm{C}$ ice core. We finally discuss how our findings are related to other hypotheses on the MPT.

\section{Introduction}

More than six decades ago Milutin Milankovitch proposed that variations in the orbital parameters of the Earth might be responsible for glacial/interglacial (G/IG) transitions in climate occurring on timescale of $10^{5}$ to $10^{6}$ years (Milankovitch, 1941). Thirty-five years later, the work of Hays et al. (1976) showed that similar frequencies of approximately $20 \mathrm{kyr}, 40 \mathrm{kyr}$, and $100 \mathrm{kyr}$ are found in the orbital variations and a deep ocean sediment record covering the last $430 \mathrm{kyr}$ and thus Milankovitch's idea was for the first time supported by a data set. Nevertheless, already in this first work which connected insolation and climate response, the power in the 1/100-kyr frequency of the orbital variations was much smaller than in the climate signal recorded in the sediment. Since then strong nonlinear feedbacks in the climate system are called for to explain this dominant 100-kyr frequency which is found in most climate records covering approximately the last $1 \mathrm{Myr}$ (e.g. Imbrie et al., 1993). Furthermore, the origins of the 100-kyr cycles are interactions of different planets in our solar system leading to eccentricity anomalies in at least five different independent periods between 95 and $107 \mathrm{kyr}$ (Berger et al., 2005). It is also long known that climate reconstructions which go further back in

Published by Copernicus Publications on behalf of the European Geosciences Union. 


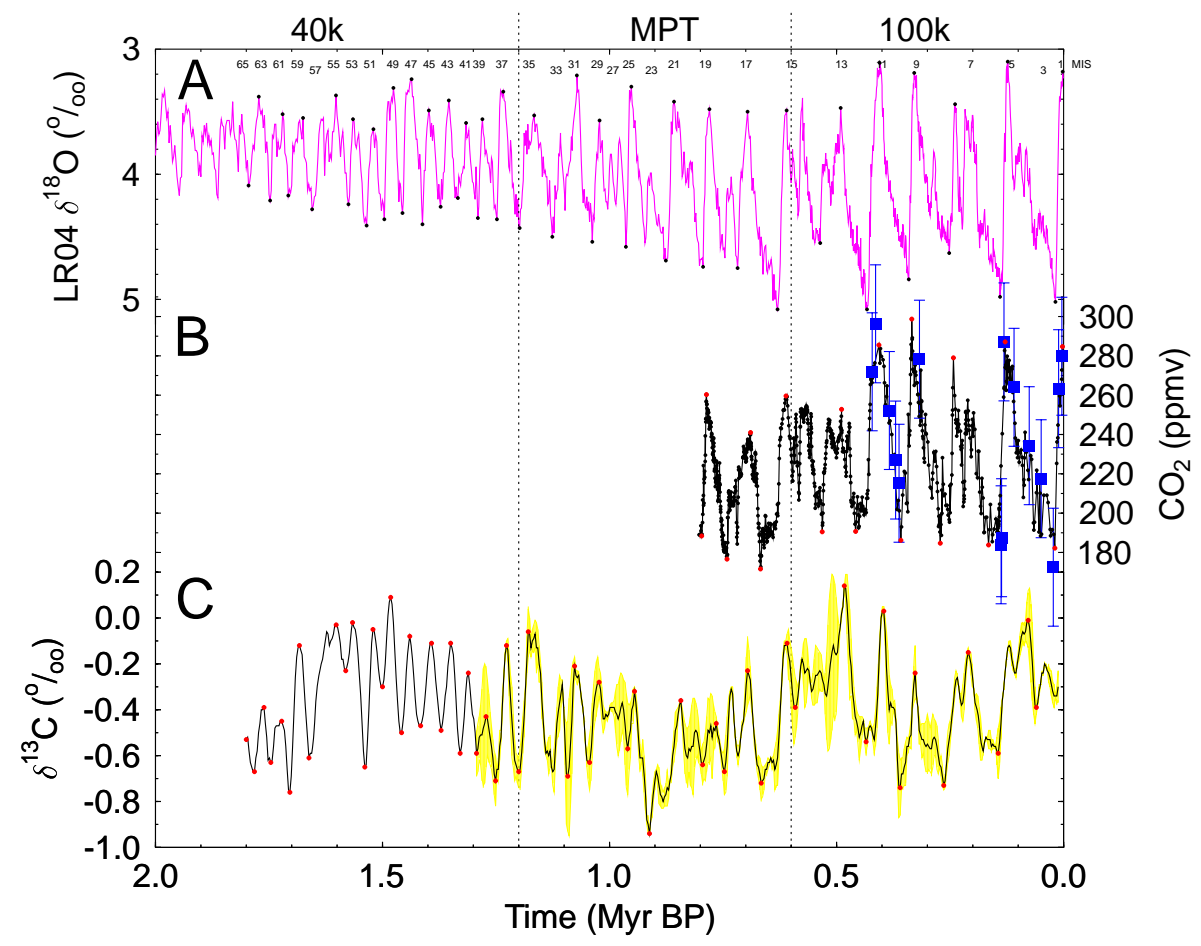

Fig. 1. Data evidences for changes in the climate system and the global carbon cycle over the last $2 \mathrm{Myr}$. (A) LR04 benthic $\delta^{18} \mathrm{O}$ stack (Lisiecki and Raymo, 2005). Odd MIS during the last 1.8 Myr are labelled. Those MIS (3, 23, 27, 33, 57) not used for the calculation of G/IG amplitudes due to its weak representation in both LR04 and the Pacific $\delta^{13} \mathrm{C}$ records are offset (similar as in Raymo et al., 2004). (B) Atmospheric $\mathrm{CO}_{2}$. Ice core measurements (circles, lines) from Vostok and EPICA Dome C (Petit et al., 1999; Siegenthaler et al., 2005; Lüthi et al., 2008). Vostok $\mathrm{CO}_{2}$ on the orbitally tuned age scale (Shackleton, 2000), EPICA Dome C on the EDC3_gas_a age scale (scenario 4 in Loulergue et al., 2007; Parrenin et al., 2007b). Reconstructed $\mathrm{CO}_{2}$ (squares) based on $\mathrm{pH}$ in equatorial Atlantic waters derived from $\delta^{11} \mathrm{~B}$ measured in planktic foraminifera (Hönisch and Hemming, 2005). (C) Mean benthic $\delta^{13} \mathrm{C}$ measured from ODP846 (Raymo et al., 2004) and ODP677 (Raymo et al., 1997). The data sets of both sediment cores were interpolated at $3 \mathrm{kyr}$ steps, smoothed to a 3-point running mean and are synchronised on the orbitally tuned age scale of Shackleton et al. (1990). ODP677 covers only the last 1.3 Myr. Plotted here is the mean $\delta^{13} \mathrm{C} \pm 1 \mathrm{SD}$ (yellow). Black (A) and red (B, C) dots denote local minima/maxima within individual MIS, which were used to calculate G/IG amplitudes.

time do not show this 100-kyr variability but are dominated by the 40-kyr cycle caused by Earth's obliquity (Shackleton and Opdyke, 1976; Pisias and Moore Jr., 1981). Since then this shift in the climate from a 40-kyr variability in the Early Pleistocene (the $40 \mathrm{k}$ world) towards a 100-kyr periodicity in the last several hundreds of thousands years (the $100 \mathrm{k}$ world) was called the "Mid Pleistocene Transition (MPT)" and sometimes the "Mid Pleistocene Revolution". Besides this shift in the dominant frequency the MPT is also characterised by an increase in G/IG amplitudes in climate signals from the $40 \mathrm{k}$ to the $100 \mathrm{k}$ world, as clearly seen, for example, in the Lisiecki and Raymo (2005) LR04 benthic $\delta^{18} \mathrm{O}$ stack (Fig. 1A). A convincing theory which explains these observations remains elusive, however in recent years several hypotheses on the interpretation of the MPT were put forward (e.g. Maslin and Ridgwell, 2005; Raymo et al., 2006; Schulz and Zeebe, 2006; Clark et al., 2007; Huybers, 2007; Bintanja and van de Wal, 2008).
Interestingly, little attention has been given in most of these studies to changes in the carbon cycle. This might be based on the fact that ice core reconstructions including measurements of atmospheric $\mathrm{CO}_{2}$ are so far restricted to the last $800 \mathrm{kyr}$ covered in the Vostok and EPICA Dome C ice cores (Petit et al., 1999; Siegenthaler et al., 2005; Lüthi et al., 2008). However, it has been shown that atmospheric $\mathrm{CO}_{2}$ can be calculated from $\mathrm{pH}$ reconstructions based on boron isotopes (Hönisch and Hemming, 2005) and thus the limitation in the extension of the $\mathrm{CO}_{2}$ time series given by the retrieval of old ice cores might at least be partially compensated in the near future (Fig. 1B). Furthermore, there is ample information on carbon cycle dynamics in published benthic $\delta^{13} \mathrm{C}$ reconstructions. From these benthic $\delta^{13} \mathrm{C}$ records at least long-term trends during the past $1.2 \mathrm{Myr}$ were investigated recently (Hoogakker et al., 2006).

We here extend on the interpretation of carbon cycle dynamics across the MPT, but concentrate on the G/IG amplitudes. For this aim we perform simulations with the global carbon cycle box model BICYCLE. BICYCLE was the 
only full carbon cycle model used in the "EPICA challenge" (Wolff et al., 2004, 2005; Köhler and Fischer, 2006) "to predict based on current knowledge, what carbon dioxide" further back in time "will look like". This challenge was started after the publication of climate signals of EPICA Dome C covering eight glacial cycles (EPICA-community-members, 2004), but before the presentation of any of the $\mathrm{CO}_{2}$ data extending Vostok's $\mathrm{CO}_{2}$ record beyond $400 \mathrm{kyr}$ BP (Siegenthaler et al., 2005; Lüthi et al., 2008). As older ice cores are planned to be drilled in the near future (Brook et al., 2006), this study can therefore be understood as an extension of the "EPICA challenge" further back in time. However, for the time being our results here will focus on the interpretation of measured benthic $\delta^{13} \mathrm{C}$ of the deep Pacific Ocean (Fig. 1C). Finally, we will discuss our results in the context of various recently published hypotheses on the causes of the MPT.

\section{Methods}

\subsection{The model BICYCLE}

To investigate the consequences of changes in climate on the carbon cycle across the MPT we use the carbon cycle box model BICYCLE (Fig. 2). It consists of a ten reservoir ocean module, one well mixed atmospheric box and a globally averaged terrestrial biosphere represented by seven boxes which distinguish $\mathrm{C}_{3}$ and $\mathrm{C}_{4}$ photosynthesis, and soils with different turnover times (Köhler and Fischer, 2004; Köhler et al., 2005). Prognostic variables are carbon (DIC in the ocean), $\delta^{13} \mathrm{C}$ and $\Delta{ }^{14} \mathrm{C}$ in all boxes, and additionally alkalinity, $\mathrm{PO}_{4}$ and $\mathrm{O}_{2}$ in the ocean boxes. The model is based on former box models of the ocean (Munhoven, 1997) and the terrestrial biosphere (Emanuel et al., 1984), but was adapted and updated in previous studies. So far, BICYCLE was applied to understand carbon cycle dynamics during Termination I (Köhler and Fischer, 2004; Köhler et al., 2005), participated in the EPICA challenge (Wolff et al., 2005; Köhler and Fischer, 2006), and was used for the interpretation of atmospheric $\delta^{13} \mathrm{C}$ and $\Delta^{14} \mathrm{C}$ (Köhler et al., 2006a,b).

We use a model configuration which differs only slightly from previous applications in the definition of water fluxes between ocean reservoirs. In earlier applications all of the upwelling water in the Southern Ocean was travelling through the Southern Ocean surface box. Here, 30\% of the upwelling flux is immediately relocated to the intermediate box in the equatorial Atlantic (dashed lines in Fig. 2). This is reasoned with the short residence time of these waters at the surface which is too short for equilibration with the atmosphere. With this model revision the results for atmospheric $p \mathrm{CO}_{2}$ are $\sim 10 \mu \mathrm{atm}$ lower during glacial maximums, which is still within the uncertainty range given by the ice core measurements (see Sect. 3.2). However, the revision brings the simulated $\delta^{13} \mathrm{C}$ in the deep ocean closer to paleo reconstructions.

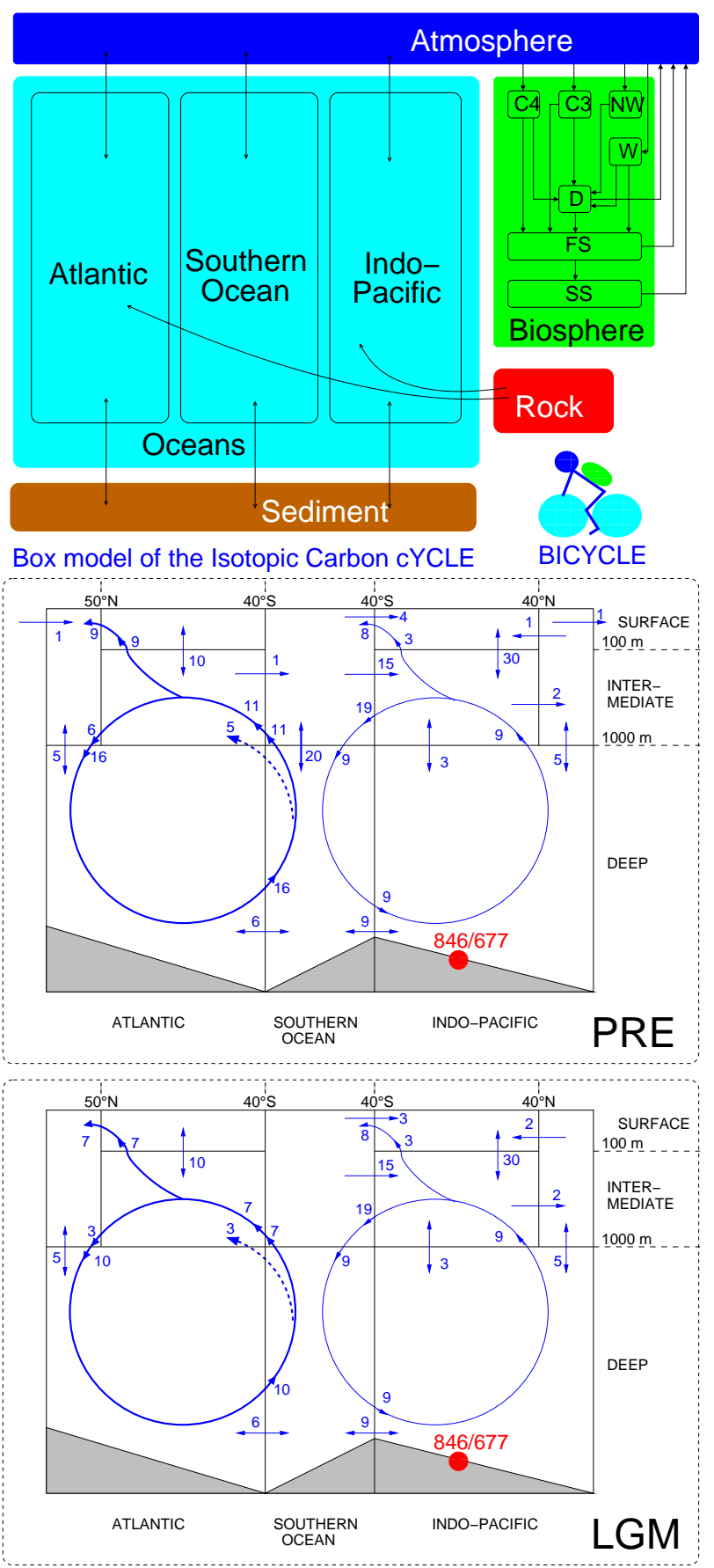

Fig. 2. The BICYCLE carbon cycle model. Top: Main geometry. Middle and bottom: Geometry and ocean circulation fluxes (in $\mathrm{Sv}=10^{6} \mathrm{~m}^{3} \mathrm{~s}^{-1}$ ) of the oceanic module. PRE: preindustrial circulation based on the World Ocean Circulation Experiment WOCE (Ganachaud and Wunsch, 2000). LGM: assumed circulation during the LGM. The latitudinal position of the sediment cores in the equatorial Pacific ODP677/846 used for comparison is indicated by the red dot. 


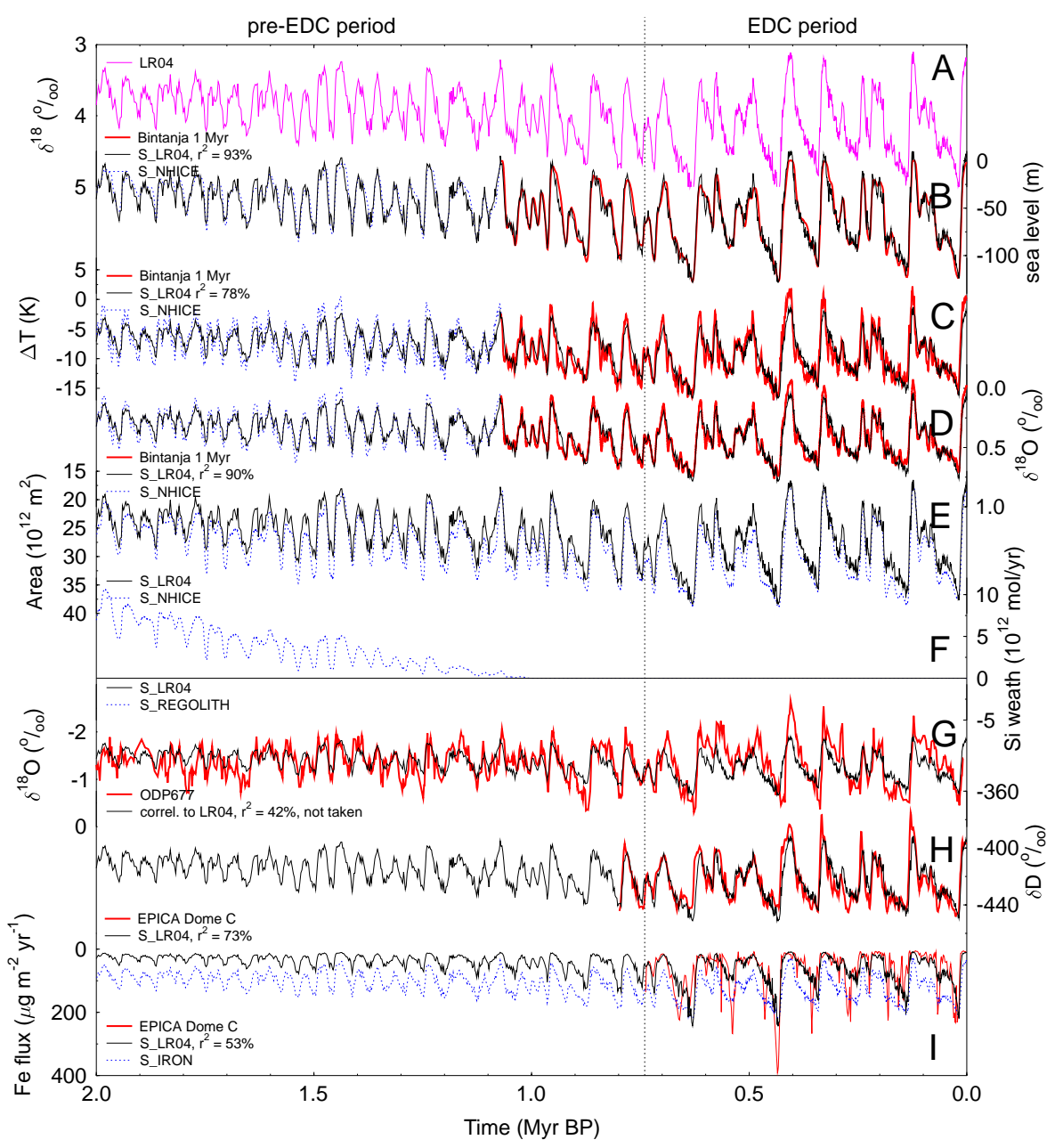

Fig. 3. Paleo-climatic records which were used to force the BICYCLE model. Original records (red, bold), those calculated from correlations with LR04, used in scenario S_LR04 (black, thin), and alternative forcings (blue, broken). (A) LR04 benthic $\delta^{18} \mathrm{O}$ stack (Lisiecki and Raymo, 2005). (B) Sea level changes. (C) Temperature changes over land in the Northern Hemisphere $\left(40-80^{\circ} \mathrm{N}\right)$. (D) Variability in deep ocean $\delta^{18} \mathrm{O}$ caused by deep ocean temperature changes. (E) Changes in areal extent of northern hemispheric ice sheets. (F) Additional silicate weathering flux due to regolith erosion. (G) Planktic $\delta^{18} \mathrm{O}$ of ODP677 $\left(1^{\circ} 12^{\prime} \mathrm{N}, 83^{\circ} 44^{\prime} \mathrm{W}\right)$ (Shackleton et al., 1990). (H) Sea level corrected deuterium $\delta$ D. (I) Atmospheric iron fluxes to Antarctica. B-D: 1 Myr after Bintanja et al. (2005), 2-1 Myr BP and (E) after Bintanja and van de Wal (2008). H-I as measured in the EPICA Dome C ice core (EPICA-community-members, 2004; Wolff et al., 2006).

Assumed temporal changes in ocean circulation are (i) a highly stratified glacial Southern Ocean with less vertical exchange, (ii) a reduced North Atlantic Deep Water (NADW) formation and subsequent fluxes during glacials, and (iii) a closure of the Bering Strait during glacials caused by their sea level low stands (Fig. 2). The strength of the vertical mixing flux in the Southern Ocean is linearly coupled to the variability in the Southern Ocean SST (Fig. 3H). The mixing flux is not allowed to exceed preindustrial values and to be consistent with previous studies (Köhler et al., 2005) is not allowed below its assumed minima at LGM (Fig. 4C). NADW formation and Bering Strait outflow switch only between glacial and interglacial states. Their changes are trig- gered by northern hemispheric temperature (Fig. 3C). Thus, the strong Atlantic overturning depicted in Fig. 2A exists only during peak interglacial conditions (Fig. 4B).

For the analysis of the ${ }^{13} \mathrm{C}$ cycle in the deep ocean a sediment box with initially $50000 \mathrm{PgC}$ and a $\delta^{13} \mathrm{C}$ of $2.75 \%$ o is introduced in each deep ocean basin (Atlantic, Southern Ocean, Indo-Pacific). The initial $\delta^{13} \mathrm{C}$ of the sediments is similar to the long-term average signature of the $\mathrm{CaCO}_{3}$ produced in the surface ocean. Initial values were chosen such that the $\delta^{13} \mathrm{C}$ signature of the sediments does not present any large drift, they change in the chosen setting less than $\pm 0.04 \%$ over the simulation period. If the initial $\delta^{13} \mathrm{C}$ in the sediments is, for example, smaller than that of the exported 


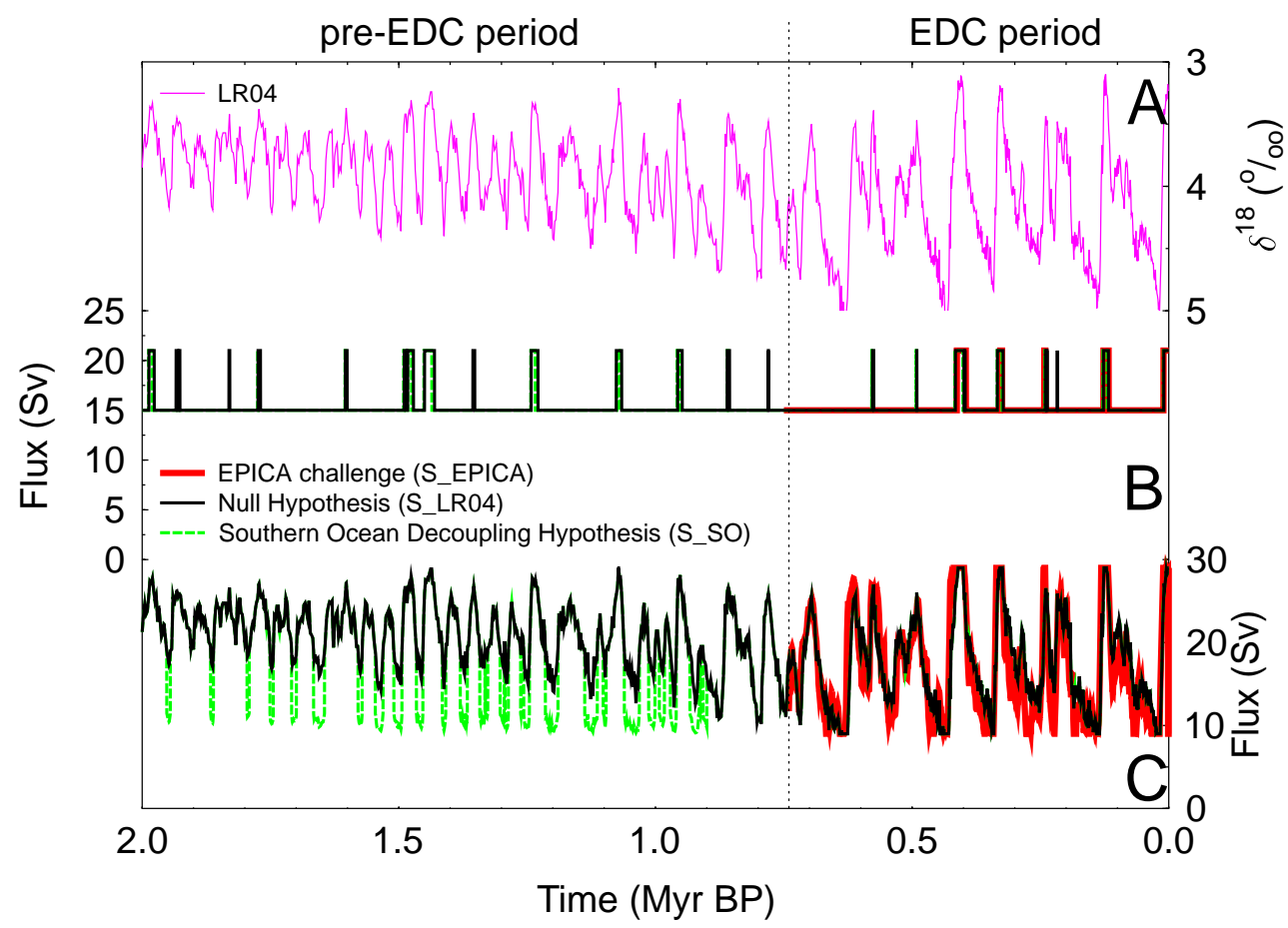

Fig. 4. Time series of surface to deep ocean fluxes in the North Atlantic (B) and the Southern Ocean (C) for different scenarios. Note, that plotted numbers sum up all fluxes, e.g. deep water formation and vertical mixing fluxes. After 0.9 Myr BP the fluxes in the Southern Ocean for S_LR04 and S_SO are identical. (A) LR04 benthic $\delta^{18} \mathrm{O}$ stack (Lisiecki and Raymo, 2005) for comparison.

and accumulated $\mathrm{CaCO}_{3}$, sedimentary $\delta^{13} \mathrm{C}$ increases over time (e.g. $+0.25 \%$ over $2 \mathrm{Myr}$ for initially $1 \%$ o lower $\delta^{13} \mathrm{C}$ in the sediments), while that of the ocean/atmosphere/biosphere decreases (mean ocean by $-0.02 \%$ o for the same example). The $\mathrm{CaCO}_{3}$ which enters the deep ocean boxes and can be accumulated in the sediments, was produced with a fixed ratio between export of organic matter $(\mathrm{OM})$ and hard shells in the surface waters $\left(\mathrm{C}_{\mathrm{OM}}: \mathrm{C}_{\mathrm{CaCO}_{3}}=10: 1\right)$. $\mathrm{C}_{\mathrm{OM}}$ export at $100 \mathrm{~m}$ depth is prescribed for present day to $10 \mathrm{PgC}$ (e.g. Schlitzer, 2000), but depends on available macro-nutrients. This is realised with maximum productivity in equatorial waters. Increased export might occur in the Southern Ocean, if macronutrients are available and the proxy for iron input into the Southern Ocean suggests the stimulation of additional productivity due to iron fertilisation. The chosen export production of organic matter and rain ratio lead to modern $\mathrm{CaCO}_{3}$ export of $1 \mathrm{PgC} \mathrm{yr}^{-1}$ similar to other applications (e.g. Jin et al., 2006). $\mathrm{CaCO}_{3}$ is partially (20\%) remineralised in the intermediate layers. In the deep ocean carbonate compensation is calculated with a relaxation approach resulting in either sedimentation of $\mathrm{CaCO}_{3}$ or dissolution of sediments as a function of the offset from initial (present day) $\mathrm{CO}_{3}^{2-}$ concentrations. This relaxation approach considers a slow time delayed response of the sediments to deep ocean carbonate ion anomalies with an e-folding time of $1.5 \mathrm{kyr}$ to be in line with data-based reconstructions (Marchitto et al., 2005).
During sedimentation and dissolution no isotopic fractionation is assumed: $\mathrm{CaCO}_{3}$ which is added to the sediments has the same $\delta^{13} \mathrm{C}$ as during hard shell production at the water surface, while the dissolved carbonate carries the $\delta^{13} \mathrm{C}$ signal of the sediment box.

\subsection{Time-dependent forcing}

For the applications of BICYCLE over the last $740 \mathrm{kyr}$ (Köhler and Fischer, 2006) various proxy data sets derived from sediment and ice cores were used to force it with timedependent climatic boundary conditions. The success of this approach depends heavily on the synchronisation of the used data sets onto a common time scale. Due to this intrinsic feature of the forcing mechanisms and the restriction of Antarctic ice core records to the last $800 \mathrm{kyr}$ we relied on a simple, but more consistent approach to force our model over the last 2 Myr.

This new approach is based on the use of the benthic $\delta^{18} \mathrm{O}$ stack LR04 derived by Lisiecki and Raymo (2005) as a master record for any observed climatic change. We calculate regression functions between LR04 and all those records used to force the model over the last $740 \mathrm{kyr}$ (Table 1 and Figs. A1-A6 in the Supplemental Material http://www.clim-past.net/4/311/ 2008/cp-4-311-2008-supplement.pdf). These regression 
Table 1. Regression functions calculated between LR04 benthic $\delta^{18} \mathrm{O}$ (variable $x$ ) (Lisiecki and Raymo, 2005) and the mentioned paleo records. All EPICA Dome C records were taken on the EDC3 age scale (Parrenin et al., 2007a). Complete time series are found in the supplement.

\begin{tabular}{|c|c|c|c|c|c|}
\hline Record (variable $y$ ) & Symbol & $\begin{array}{c}\text { Length } \\
\text { (kyr) }\end{array}$ & Regression function & $\begin{array}{l}r^{2} \\
(\%)\end{array}$ & Reference \\
\hline Sea level & LR04-SEAL & 1070 & $y=234.51-71.41 \cdot x$ & 93 & Bintanja et al. (2005) \\
\hline Northern hemispheric temperature & LR04-NHdT & 1070 & $y=22.74-7.75 \cdot x$ & 78 & Bintanja et al. (2005) \\
\hline$\Delta \delta^{18} \mathrm{O}$ of LR04 caused by deep sea temperature & LR04-DEEPdT & 1070 & $y=-1.12-0.38 \cdot x$ & 90 & Bintanja et al. (2005) \\
\hline$\delta \mathrm{D}$ in EPICA Dome C (SO SST proxy) & LR04-dD & 800 & $y=-298.00-30.10 \cdot x$ & 73 & Jouzel et al. (2007) \\
\hline Fe flux in EPICA Dome C (SO Fe fertilisation proxy) & LR04-FE1 & 740 & $y=10^{-1.36+0.74 \cdot x}$ & 53 & Wolff et al. (2006) \\
\hline Fe flux in EPICA Dome C (SO Fe fertilisation proxy $)^{a}$ & LR04-FE2 & 740 & $y=-279.34+98.12 \cdot x$ & 13 & Wolff et al. (2006) \\
\hline Planktic $\delta^{18} \mathrm{O}$ in ODP667 (equatorial SST proxy) & LR04-EQSST & 2000 & $y=-3.84-0.63 \cdot x$ & 42 & Shackleton et al. (1990) \\
\hline
\end{tabular}

${ }^{\mathrm{a}}$ Linear regression only for points with Fe flux $\geq 100 \mu \mathrm{g} \mathrm{m}^{-2} \mathrm{yr}^{-1}$.

functions are then used to extrapolate how the various components of the Earth's climate, which are used as changing boundary conditions in our carbon cycle model, might have changed over the last $2 \mathrm{Myr}$. Although this approach neglects any existing leads and lags between various parts of the climate system, it should in the light of the relatively coarse temporal resolution of LR04 ( $\Delta t=1-2.5 \mathrm{kyr}$ between $2 \mathrm{Myr}$ and present) be a good approximation to estimate $\mathrm{G} / \mathrm{IG}$ changes. Furthermore, it implies that the correlation of the various paleo records with LR04 were in principle not different before and after the MPT and that the undertaken extrapolation of the forcings to $2 \mathrm{Myr}$ is meaningful. It also implies that climate processes and their impacts on the carbon cycle were following similar functional dependencies in the $40 \mathrm{k}$ and the $100 \mathrm{k}$ world. Therefore, we refer to this approach, which is heavily based on forcing functions derived from LR04 (scenario S_LR04) as our "Null Hypothesis". The comparison of model results of this Null Hypothesis (S_LR04) with those of the scenarios forced with the original records (S_EPICA: original $740 \mathrm{kyr}$ application; S_EPICA+: $740 \mathrm{kyr}$ application with revised ocean circulation) gives us evidences how much variability in the carbon cycle will be lost by the simplification of the forcing mechanisms. Thus, this comparison represents a sort of "groundtruthing" which is important for the interpretation of the results going further back in time than 740 kyr BP.

The correlation of the regressions functions between LR04 and the other records is in general high $\left(r^{2}\right.$ of $76 \%$ to $93 \%$, Table 1). The poorest correlations ( $r^{2}$ of $42 \%$ and $52 \%$ ) exist for LR04 and planktonic $\delta^{18} \mathrm{O}$ in ODP667 (a proxy for equatorial SST) and for LR04 and the iron flux as measured in the EPICA Dome $\mathrm{C}$ ice core (a proxy for iron input into the Southern Ocean). Due to this relatively bad correlation and the fact that the record of planktonic $\delta^{18} \mathrm{O}$ in ODP667 is available over the whole $2 \mathrm{Myr}$ time window we refrain from using the LR04-based substitute, but use the original $\delta^{18} \mathrm{O}$ data from ODP667 throughout our simulations. Fur- thermore, it was shown (Liu et al., 2008) that tropical SST dynamics across the MPT are different than global climate variations contained in LR04. This is another argument to rely on the original record in the equatorial region.

The second correlation with low $r^{2}$ determines variations in the size of the marine export production in the Southern Ocean and is responsible for the simulated rise of atmospheric $p \mathrm{CO}_{2}$ of up to $20 \mu \mathrm{atm}$ during Termination I (Köhler et al., 2005). Furthermore, for all forcing records but the iron flux record linear regression functions led to adequate result. The regression between the iron flux and LR04 needs the use of an exponential regression function. Because of the poor correlation of these two records and the potential consequences of this for biologically driven carbon export to the ocean interior an alternative scenario S_IRON is applied, in which changes during peak iron fluxes are better represented than previously. This is achieved through a linear regression between LR04 and the iron flux that is restricted to iron fluxes $\geq=100 \mu \mathrm{g} \mathrm{m}^{2} \mathrm{yr}^{-1}$ (Fig. 3I). These iron peaks are of special interest because it can be assumed that during these times the Southern Ocean marine biology was not limited by iron and thus export production was enhanced (Martin, 1990; Parekh et al., 2008).

Furthermore, changes in various climate variables (sea level, northern hemispheric temperature, deep sea temperature) were already estimated out of LR04 using an inverse modelling approach (Bintanja et al., 2005) for the $740 \mathrm{kyr}$ long application of the BICYCLE model. The basis of their approach is the deconvolution of the temperature and sea level information contained in $\delta^{18} \mathrm{O}$ of the LR04 stack. Bintanja and van de Wal (2008) use the same methodology, but extend the analysis $3 \mathrm{Myr}$ back in time. Here, the North American ice sheets play a central role in intensifying and prolonging the glacial cycles during the MPT. Long-term climate cooling enables the North American ice sheets to grow in the $100 \mathrm{k}$ world to a stage in which they are able to merge, after which they can grow even more rapidly until basal- 
Table 2. Summary and description of simulation scenarios.

\begin{tabular}{|c|c|c|}
\hline Name & Forcing & Comment \\
\hline \multicolumn{3}{|c|}{740 kyr simulations ( $100 \mathrm{k}$ world only) } \\
\hline S_EPICA & as in original EPICA challenge, forced with different paleo records & published in Köhler and Fischer (2006) \\
\hline S_EPICA+ & similar to S_EPICA, but with revised Southern Ocean upwelling (Fig. 2) & \\
\hline \multicolumn{3}{|c|}{ Scenarios across MPT based on previous hypotheses } \\
\hline S_LR04 & $\begin{array}{l}\text { forced with time series derived via correlation and regression function } \\
\text { between LR04 and climate records used in S_EPICA }\end{array}$ & Our Null Hypothesis \\
\hline S_IRON & $\begin{array}{l}\text { as } \mathrm{S} \_ \text {LR04, but with alternative regression function for the input of iron } \\
\text { in the Southern Ocean with consequences for marine export production }\end{array}$ & \\
\hline S_NHICE & $\begin{array}{l}\text { as S_LR04, but the smaller G/IG amplitudes in sea level change in } \\
\text { the } 40 \mathrm{k} \text { world are mainly caused by Northern Hemisphere ice volume } \\
\text { anomaly. Sea level, deep ocean and northern hemispheric temperature, } \\
\text { and areal extent of ice sheets are not obtained from correlation with } \\
\text { LR04, but taken from the cited simulation study }\end{array}$ & $\begin{array}{l}\text { input from Bintanja and van de Wal } \\
\text { (2008) }\end{array}$ \\
\hline S_REGOLITH & $\begin{array}{l}\text { as } \mathrm{S} \_ \text {NHICE, but additionally changing silicate weathering rates be- } \\
\text { tween } 2 \text { and } 1 \mathrm{Myr} \text { BP are considered }\end{array}$ & $\begin{array}{l}\text { following the Regolith Hypothesis of } \\
\text { Clark et al. (2007) }\end{array}$ \\
\hline S_COM & $\begin{array}{l}\text { combining S_LR04 with improvements of scenarios S_IRON, } \\
\text { S_NHICE, and S_REGOLITH }\end{array}$ & \\
\hline \multicolumn{3}{|c|}{ Scenarios across MPT based on our new Southern Ocean Decoupling Hypothesis } \\
\hline S_SO & $\begin{array}{l}\text { as S_LR04, but with revised (larger than in S_LR04) G/IG amplitudes } \\
\text { in the Southern Ocean vertical mixing rates before } 900 \mathrm{kyr} \text { BP }\end{array}$ & $\begin{array}{l}\text { Our Southern Ocean Decoupling Hy- } \\
\text { pothesis }\end{array}$ \\
\hline S_FINAL & $\begin{array}{l}\text { combining S_COM with S_SO, or improving the Null Hypothesis } \\
\text { with the alternative regression function for iron input in the Southern } \\
\text { Ocean (S_IRON), details on northern hemispheric ice sheet evolution } \\
\text { (S_NHICE), the Regolith Hypothesis (S_REGOLITH) and the Southern } \\
\text { Ocean Decoupling Hypothesis (S_SO) }\end{array}$ & our final (best guess) scenario \\
\hline
\end{tabular}

sliding related instabilities in this huge ice sheet causes catastrophic collapse and deglaciation. The variables mentioned above and changes in northern hemispheric ice sheet area, necessary for the areal extent of the terrestrial biosphere, calculated by Bintanja and van de Wal (2008) out of LR04, will be used alternatively in scenario S_NHICE (Fig. 3B-E).

Further changes in the carbon cycle are performed in scenario S_REGOLITH. Following the Regolith Hypothesis of Clark et al. (2007) we assume that the regolith layer located beneath the northern hemispheric ice sheets got eroded over time before the MPT. This leads to an additional flux of silicate weathering or $\mathrm{HCO}_{3}^{-}$input to the ocean. We assume a weathering and thus $\mathrm{HCO}_{3}^{-}$flux, which declines over time (from $12 \times 10^{12} \mathrm{~mol} \mathrm{Cyr}^{-1}(2 \mathrm{Myr} \mathrm{BP})$ to $0 \mathrm{~mol} \mathrm{C} \mathrm{yr}^{-1}$ $-1 \mathrm{Myr} \mathrm{BP})$, and which is modulated by the areal extent of the northern hemispheric ice sheets (Fig. 3F). The carbonate chemistry of the ocean (including the magnitude of the carbonate compensation) is effected by these fluxes as they change the overall budgets of alkalinity and DIC. These numbers consider only the additional changes in the weathering rate, thus background silicate and carbonate weathering is implicitly included in our carbonate compensation mecha- nism. It has been shown that to obtain stable atmospheric $\mathrm{CO}_{2}$ on time scales longer than glacial cycles volcanic outgassing and weathering fluxes balance each other (e.g. Zeebe and Caldeira, 2008). This implies that half of the carbon consumed by silicate weathering need to be supplied by volcanic out-gassing of $\mathrm{CO}_{2}$, while the other half is taken from atmospheric $\mathrm{CO}_{2}$ (Munhoven and François, 1996, and references therein). The strength of the assumed fluxes are somewhat different than those used in Clark et al. (2007). The magnitude of the additional $\mathrm{HCO}_{3}^{-}$input at $2 \mathrm{Myr} \mathrm{BP}$

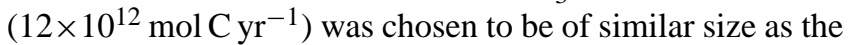
estimated present-day fluxes given by Gaillardet et al. (1999). This would imply that at $2 \mathrm{Myr} \mathrm{BP}$, at the time of maximum input of silicate weathering from regolith erosion, the amplitude of this process is twice that during present day. According to our understanding this would be a rough conservative estimate of the upper end of what impact can be expected from the Regolith Hypothesis on the global carbon cycle.

For the time being these scenarios, which are all well supported by other studies, were chosen as starting point. We will in the evaluation of these scenarios (Sects. 3.3-3.4) have to conclude that they are insufficient to describe the actual 
Table 3. A compilation how boundary conditions (climate variables) were substituted in this application.

\begin{tabular}{|c|c|c|c|c|}
\hline Climate variable & $\begin{array}{l}\text { Substitution } \\
\text { used in S_LR04 }\end{array}$ & Alternative formulation & $\begin{array}{l}\text { Scenarios which use } \\
\text { alternative formulation }\end{array}$ & Fig. ${ }^{b}$ \\
\hline Sea level & LR04-SEAL & $2 \mathrm{Myr}$ simulation results ${ }^{\mathrm{c}}$ & S_NHICE, S_REGOLITH, S_COM, S_FINAL & B \\
\hline SST (North Atlantic) ${ }^{\mathrm{d}}$ & $f$ (LR04-NHDT) & $2 \mathrm{Myr}$ simulation results ${ }^{\mathrm{c}}$ & S_NHICE, S_REGOLITH, S_COM, S_FINAL & $\mathrm{C}$ \\
\hline SST (Equatorial Atlantic) & \multicolumn{3}{|c|}{ no substitution, take original record (ODP677) } & $\mathrm{G}$ \\
\hline SST (Southern Ocean) $)^{\mathrm{e}}$ & $f(\mathrm{LR} 04-\mathrm{dD})$ & Mixing decoupled from SO SST ${ }^{\mathrm{e}}$ & S_SO, S_FINAL & $\mathrm{H}$ \\
\hline SST (Equatorial Pacific) & \multicolumn{3}{|c|}{ no substitution, take original record (ODP677) } & $\mathrm{G}$ \\
\hline SST (North Pacific) & $f($ LR04-NHDT) & $2 \mathrm{Myr}$ simulation results $\mathrm{c}^{\mathrm{c}}$ & S_NHICE, S_REGOLITH, S_COM, S_FINAL & $\mathrm{C}$ \\
\hline Intermediate and deep ocean $\mathrm{T}$ & LR04-DEEPdT & 2 Myr simulation results ${ }^{\mathrm{c}}$ & S_NHICE, S_REGOLITH, S_COM, S_FINAL & $\mathrm{D}$ \\
\hline Fe fertilisation Southern Ocean & LR04-FE1 & LR04-FE2 & S_IRON, S_COM, S_FINAL & I \\
\hline Northern hemispheric temperature & LR04-NHdT & $2 \mathrm{Myr}$ simulation results $\mathrm{c}^{\mathrm{c}}$ & S_NHICE, S_REGOLITH, S_COM, S_FINAL & $\mathrm{C}$ \\
\hline Northern hemispheric ice sheet area & $f($ LR04-SEAL) & 2 Myr simulation results ${ }^{\mathrm{c}}$ & S_NHICE, S_REGOLITH, S_COM, S_FINAL & $\mathrm{E}$ \\
\hline Silicate weathering (regolith erosion) & - & linear decline $\times$ ice sheet area & S_REGOLITH, S_COM, S_FINAL & $\mathrm{F}$ \\
\hline
\end{tabular}

a Symbols taken from Table 1.

b Notation of sub-figures of Fig. 3 where the relevant time series are plotted.

c Bintanja and van de Wal (2008).

d North Atlantic deep water formation is coupled to North Atlantic SST.

e Southern Ocean vertical mixing is coupled to SST. This coupling is linear for 900-0 kyr BP, but follows at different pattern in earlier times. Before 900 kyr BP the reduction in vertical mixing in the Southern Ocean in glacials is larger than in the SST substitute. Vertical mixing (Fig. 4C) then follows a synthetic time series, which was derived in four steps:

(1) The surrogate of LR04 for Southern Ocean SST $f(\mathrm{LR04-dD})=y_{1}$ is linearly transformed to [0, 1]:

$\left(y_{2}=f\left(y_{1}\right)\right.$ with $y_{2}(t=0 \mathrm{kyr} \mathrm{BP})=0$ and $\left.\left(y_{2}(t=18 \mathrm{kyr} \mathrm{BP})=1\right)\right)$.

(2) Stretch $y_{2}$ to colder climates by $y_{3}=\left(y_{2}\right)^{3}$. This shifts, for example, the mid point $y_{2}=0.5$ to $y_{3}=0.125$.

(3) Transfer stretched record linearly back to the range of SST values: $y_{4}=f\left(y_{3}\right)$.

(4) Restrict variations in vertical mixing to the range given by SST found at present and $17 \mathrm{kyr}$ BP, as deduced for Termination I in Köhler et al. (2005).

variability in benthic $\delta^{13} \mathrm{C}$, and at the end we will therefore make suggestions to further modify our assumptions and propose an new explanation, the Southern Ocean Decoupling Hypothesis (Sect. 3.5). All scenarios are summarised in Table 2. Details on all correlations and which variables were substituted in each scenario are described in the Tables 1 and 3 and in the Supplemental Material http://www.clim-past. net/4/311/2008/cp-4-311-2008-supplement.pdf. A detailed description how changing climatic boundary conditions impact on our carbon cycle model is published in Köhler and Fischer (2006).

\section{Results}

\subsection{Evidences from paleo records}

We concentrate our paleo data analysis across the MPT on

1. the LR04 benthic $\delta^{18} \mathrm{O}$ stack (Lisiecki and Raymo, 2005) as global recorder of climate change (Fig. 1A),

2. atmospheric $\mathrm{CO}_{2}$ measured in ice cores (Petit et al., 1999; Siegenthaler et al., 2005; Lüthi et al., 2008) (Fig. 1B),

3. reconstructed $\delta^{13} \mathrm{C}$ from the deep Pacific (Fig. 1C). Here, the deep Pacific $\delta^{13} \mathrm{C}$ is represented by an average of benthic $\delta^{13} \mathrm{C}$ measured in two cores from the equatorial Pacific (ODP846: $3^{\circ} \mathrm{S}, 91^{\circ} \mathrm{W}, 3307 \mathrm{~m}$ water depth, Raymo et al., 2004; ODP677: $1^{\circ} \mathrm{S}, 83^{\circ} \mathrm{W}, 3461 \mathrm{~m}$ water depth, Raymo et al., 1997). They are plotted on an orbital tuned age scale (Shackleton et al., 1990), were interpolated to a uniform $3 \mathrm{kyr}$ spacing and smoothed with a 3-points running mean, as performed already in Raymo et al. (2004).

We focus only on changes in $\delta^{13} \mathrm{C}$ in the deep Pacific Ocean, because changes in the Atlantic might depend largely on the core site due to changing deep and bottom water fluxes between glacial and interglacial times (Kroopnick, 1985; Curry and Oppo, 2005). These detailed changes in ocean circulation and the consequences for local $\delta^{13} \mathrm{C}$ can not be represented in our model due to the coarse spatial resolution. For the Southern Ocean not enough data sets exist to compile one record, which would be a representative of the whole Southern Ocean as it is defined in our model (south of $40^{\circ} \mathrm{S}$ ). Those long records of which we are aware are all located around $40^{\circ} \mathrm{S}$ from the South Atlantic/Atlantic sector of the Southern Ocean. In the deep eastern Pacific, where our Pacific sites are located, the horizontal and vertical gradients in $\delta^{13} \mathrm{C}$ in the modern ocean are very small (Kroopnick, 1985) (Fig. 5). A similar uniform distribution of $\delta^{13} \mathrm{C}$ exists in large parts of the glacial Pacific (Boyle, 1992) (Fig. 5). Therefore, observed changes are assumed to be representative of basin 


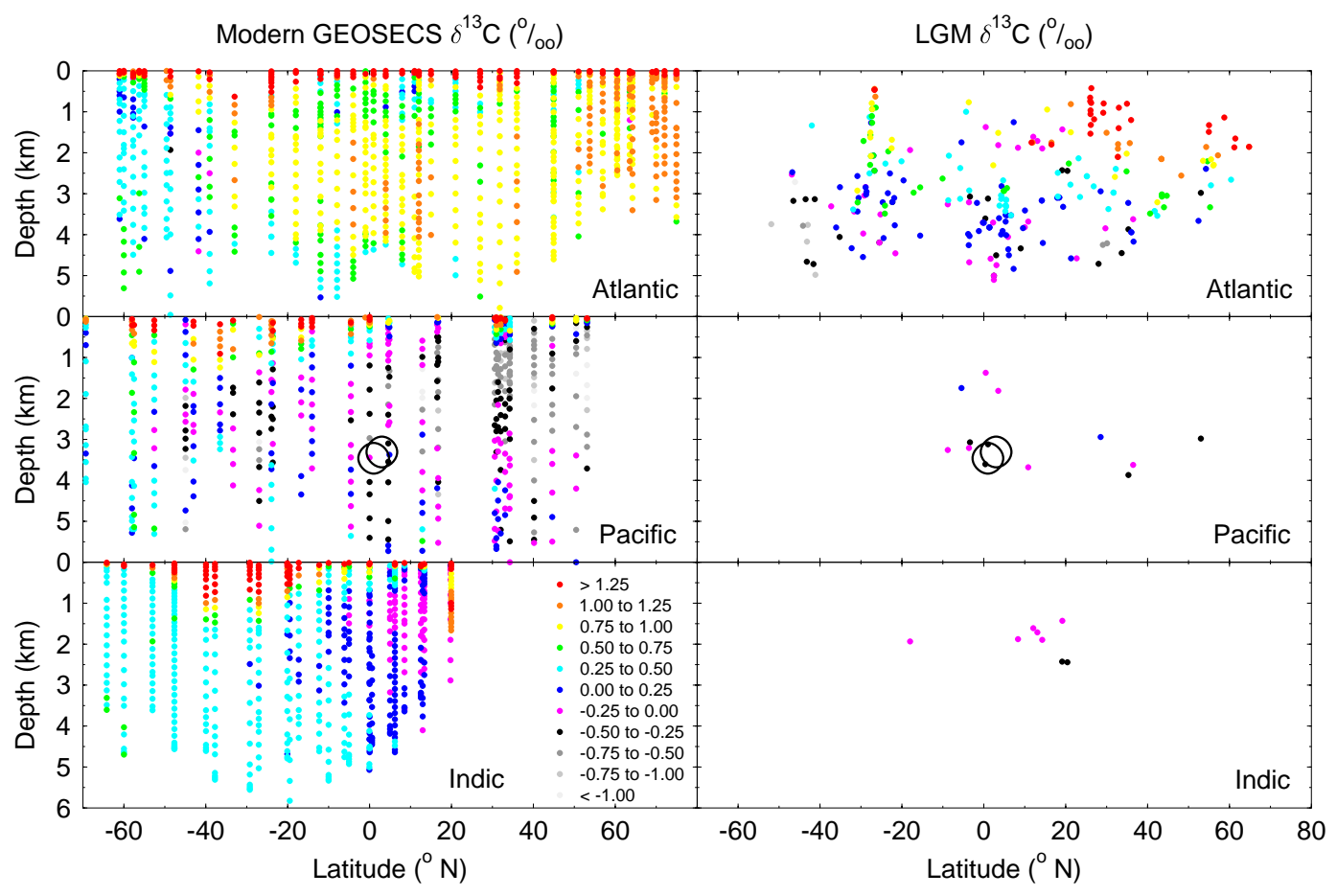

Fig. 5. Modern $\delta^{13} \mathrm{C}$ data and LGM $\delta^{13} \mathrm{C}$ reconstructions as function of ocean basin, depth and latitude. Left: GEOSECS data $\left(\delta^{13} \mathrm{C}\right.$ of DIC in the water column, Kroopnick (1985)). Right: LGM reconstructions ( $\delta^{13} \mathrm{C}$ of benthic foraminifera in sediment cores, Boyle, 1992; Bickert and Mackensen, 2004; Curry and Oppo, 2005). The reconstructions of Bickert and Mackensen (2004) are corrected for the phytodetritus effect. Circles mark the site locations of ODP846 and ODP677.

wide variations and not merely a recorder of local changes in ocean circulation. Purely local effects should be minimised by averaging two different cores.

For data analysis and the following data-model comparison we divide our time period of interest in three time windows: (a) the $40 \mathrm{k}$ world (1.8 to $1.2 \mathrm{Myr} \mathrm{BP})$, (b) the MPT (1.2 to $0.6 \mathrm{Myr} \mathrm{BP}$ ), and (c) the $100 \mathrm{k}$ world (after $0.6 \mathrm{Myr} \mathrm{BP})$. These are the same intervals as in Raymo et al. (2004) to allow comparison. Simulation results between 2.0 and $1.8 \mathrm{Myr} \mathrm{BP}$ are omitted in our further analysis due to the missing benthic $\delta^{13} \mathrm{C}$ data.

We use the maximum entropy spectral analysis (MESA) (Ghil et al., 2002) to clearly identify the MPT with its shift from $40-\mathrm{kyr}$ to 100 -kyr periodicity in the LR04 $\delta^{18} \mathrm{O}$ stack (Fig. 6A-C, see also Lisiecki and Raymo, 2007). The benthic $\delta^{13} \mathrm{C}$ in the deep Pacific as representative of the carbon cycle does also record this transition from the $40 \mathrm{k}$ to the $100 \mathrm{k}$ world (Fig. 6D-F). There is also an even slower variability with a frequency of $\sim 1 / 500 \mathrm{kyr}^{-1}$ superimposed, however this frequency component is not statistically significant within our MESA approach. Nevertheless, a low frequency component of $1 / 400 \mathrm{kyr}^{-1}$ in $\delta^{13} \mathrm{C}$ of the deep Pacific was already identified over the last $2.4 \mathrm{Myr}$ as one of the most important frequencies in ODP677 and ODP849 $\left(0^{\circ} \mathrm{N}\right.$, $110^{\circ} \mathrm{W}, 3851 \mathrm{~m}$ water depth) (Mix et al., 1995). Furthermore, a long-term cyclicity of $\sim 500 \mathrm{kyr}$ in $\delta^{13} \mathrm{C}$ has been found in all ocean basins during the Pleistocene (Wang et al., 2004). Spectral analysis of atmospheric $\mathrm{CO}_{2}$ is omitted due to data-limitation.

The sizes of the G/IG amplitudes of the selected records for the different time windows are of special interest in this study. They are summarised together with simulation results in Table 4. Besides the averages ( \pm one standard deviation) their relative sizes during earlier times with respect to the $100 \mathrm{k}$ world is investigated. This information is expressed in the so-called $f$-ratio $\left(f_{X}=\frac{\bar{\Delta}_{X}}{\bar{\Delta}_{100 \mathrm{k}}} \cdot 100\right.$ in $\%$, with $X=$ MPT or $40 \mathrm{k}$ ). It gives information on the changes in amplitude over the MPT, and not in frequency. It will be used widely in the following to compare the qualitative behaviour of our simulations with the reconstructions. We have to acknowledge that for this analysis of G/IG amplitudes some periods (MIS $23,27,33$, and 57), in which no distinct maxima could be identified in the $\delta^{13} \mathrm{C}$ records were omitted for further analysis. All local minima and maxima used here are marked in Fig. 1.

The global climate as represented by LR04 exhibits G/IG amplitudes, which increase by up to a factor of two over the MPT. In other words, the $f$-ratios are $76 \%$ and $51 \%$ for the 

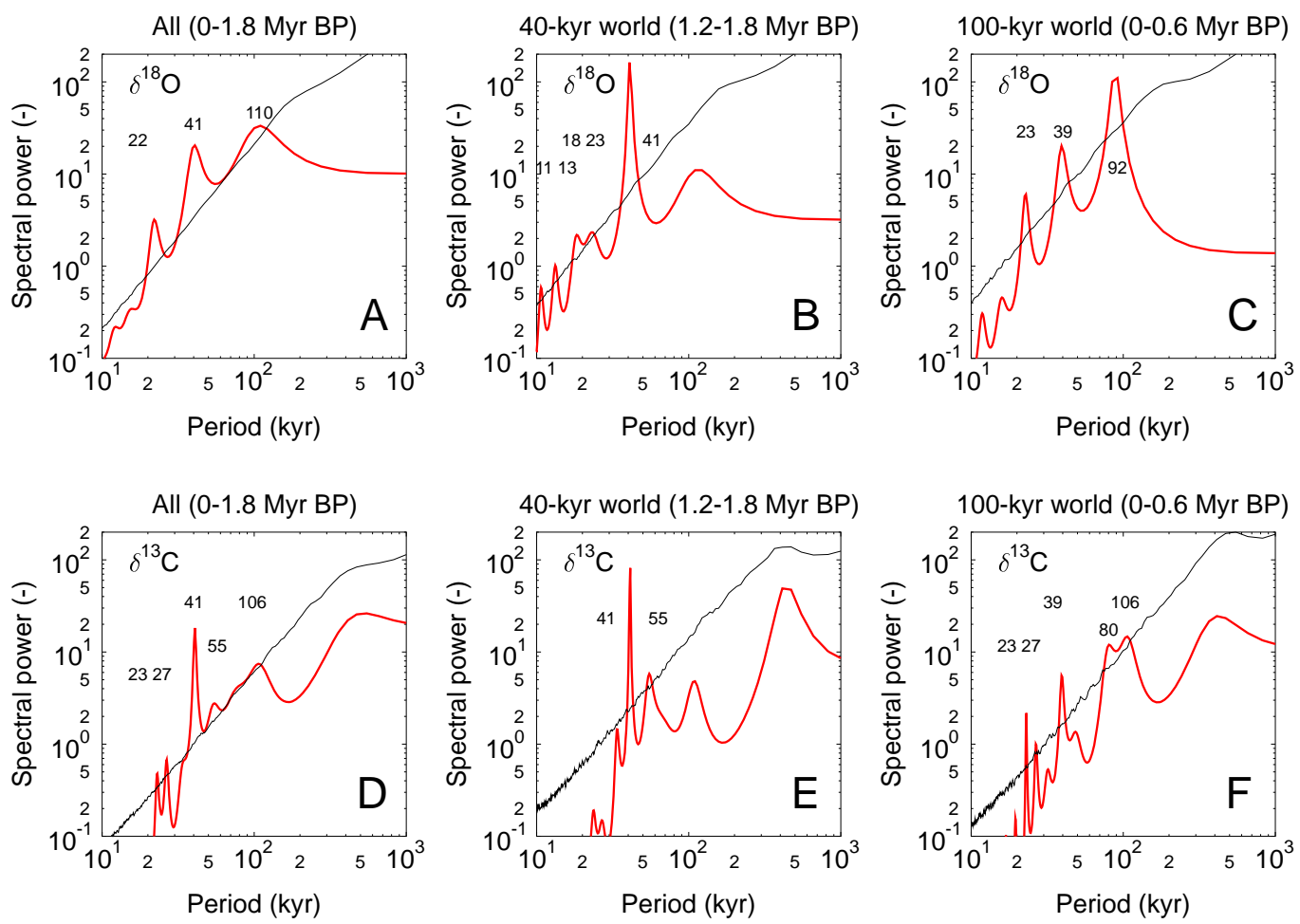

Fig. 6. Maximum entropy spectral analysis (MESA). Power spectra of the LR04 benthic $\delta^{18} \mathrm{O}$ stack (A-C) and the deep Pacific $\delta^{13} \mathrm{C}$ reconstruction (D-F) for different time windows, (time series plotted in Fig. 1A, C). Data (bold red) and their 99\% confidence (thin black). Significant periods of labelled.

MPT and the $40 \mathrm{k}$ world, respectively. Similarly, the G/IG amplitudes in the stacked Pacific $\delta^{13} \mathrm{C}$ increase over time, but not as much as the climate signal seen in LR04. Its amplitude increases from $0.40 \pm 0.16 \%$ o (40 k) via $0.44 \pm 0.15 \%$ o (MPT) to $0.55 \pm 0.03 \%$ o (100 k), corresponding to $f$-ratios of $72 \%$ (40 k) and $80 \%$ (MPT), respectively. The same analysis is performed for the two individual ODP $\delta^{13} \mathrm{C}$ time series which were averaged here, to check if and how the stacking of both $\delta^{13} \mathrm{C}$ records leads to changes in the $\mathrm{G} / \mathrm{IG}$ amplitudes. Indeed, the amplitudes in ODP677 in the $100 \mathrm{k}$ world are with $0.69 \pm 0.09 \%$ o larger than those of ODP846 $(0.49 \pm 0.12 \%)$. They seemed to be of similar amplitude in the $40 \mathrm{k}$ world ( $0.39 \%$ vs. $0.41 \%$ ), but ODP677 covers only two G/IG transitions here. The consequence is that the $f_{40 \mathrm{k}^{-}}$ ratios differ (56\% and 83\% for ODP677 and ODP846, respectively). However, because of the shortness of ODP677 $(1.3 \mathrm{Myr})$, we think the statement that Pacific benthic $\delta^{13} \mathrm{C}$ changed less in G/IG amplitudes across the MPT than LR04 is based on solid evidences.

Our data-based knowledge on variations in atmospheric $\mathrm{CO}_{2}$ is limited (Fig. 1B). Direct measurements of $\mathrm{CO}_{2}$ on air enclosures in ice cores is restricted to the last $800 \mathrm{kyr}(\mathrm{Pe}-$ tit et al., 1999; Siegenthaler et al., 2005; Lüthi et al., 2008). Within this time $\mathrm{CO}_{2}$ varies between 170 and 300 ppmv (the partial pressure of $p \mathrm{CO}_{2}$ of 170 to $300 \mu \mathrm{atm}$ ). Fur- ther evidences on $\mathrm{CO}_{2}$ variability before the MPT do not exist. One alternative approach of reconstructing $\mathrm{CO}_{2}$ is based on the surface seawater $\mathrm{pH}$, which itself is calculated out of $\delta^{11} \mathrm{~B}$ measured on planktic foraminifera (Hönisch and Hemming, 2005). Existing $\mathrm{CO}_{2}$ reconstructions are consistent with ice core measurements, but with a large error of $\pm 30 \mu \mathrm{atm}$ (Fig. 1B). This approach has nevertheless the potential to extent the $\mathrm{CO}_{2}$ ice core records further back in time in the near future. For the time being we restrict our analysis of $\mathrm{G} / \mathrm{IG}$ amplitudes in atmospheric $\mathrm{CO}_{2}$ to the ice core records. In the $100 \mathrm{k}$ world the mean $\mathrm{G} / \mathrm{IG}$ amplitude in $\mathrm{CO}_{2}$ is $95 \pm 16 \mathrm{ppmv}$. This is reduced to $75 \pm 10 \mathrm{ppmv}$ in the MPT $\left(f_{\mathrm{MPT}}=79 \%\right)$, but we have to be aware that the ice cores contain only three G/IG transitions in the MPT time window (Table 4).

3.2 Ground-truthing of our approach based on LR04 - simulations for the last $740 \mathrm{kyr}$

Detailed discussions of simulation results obtained with BICYCLE over the last $740 \mathrm{kyr}$ were already published. The previous application concentrated on atmospheric $p \mathrm{CO}_{2}$ (scenario S_EPICA, Köhler and Fischer, 2006). The ocean circulation field used in the model was revised between the earlier and the present application for an enhanced represen- 
Table 4. Analysis of G/IG amplitudes in LR04, $p \mathrm{CO}_{2}$, and deep Pacific $\delta^{13} \mathrm{C}$ for reconstructions and simulation results divided into different time windows. The $f$-ratio $\left(f_{X}=\frac{\bar{\Delta}_{X}}{\bar{\Delta}_{100 \mathrm{k}}} \cdot 100\right.$ with $X=\mathrm{MPT}$ or $40 \mathrm{k}$ ) describes the relative size (in \%) of G/IG amplitudes in comparison to the $100 \mathrm{k}$ world. The number $n$ of G/IG transitions included in theses calculations are 6 (100 k), 8 (MPT), and 13 (40k) in all entries. Only in the $\delta^{13} \mathrm{C}$ sediment cores $n$ is smaller: ODP677/846 has $n=5(100 \mathrm{k})$ due to missing data during the Holocene and thus no G/IG values for Termination I, and in ODP677 $n=2$ (40 k). Most important scenarios (our Null Hypothesis S_LR04 and our best guess scenario S_FINAL) are highlighted in bold.

\begin{tabular}{|c|c|c|c|c|c|}
\hline \multirow[t]{2}{*}{ Name } & \multirow{2}{*}{$\frac{100 \mathrm{k}}{\bar{\Delta} \pm \mathrm{SD}}$} & \multicolumn{2}{|c|}{ MPT } & \multicolumn{2}{|c|}{$40 \mathrm{k}$} \\
\hline & & $\bar{\Delta} \pm \mathrm{SD}$ & $f_{\mathrm{MPT}}$ & $\bar{\Delta} \pm \mathrm{SD}$ & $f_{40 \mathrm{k}}$ \\
\hline \multicolumn{6}{|l|}{ global climate $(\% o)$} \\
\hline LR04 & $1.60 \pm 0.34$ & $1.22 \pm 0.20$ & 76 & $0.82 \pm 0.15$ & 51 \\
\hline \multicolumn{6}{|c|}{ atmospheric $p \mathrm{CO}_{2}(\mu \mathrm{atm})$} \\
\hline Vostok + EDC & $95 \pm 16$ & $75 \pm 10^{\mathrm{a}}$ & 79 & - & - \\
\hline S_EPICA & $70 \pm 11$ & $-\mathrm{b}$ & - & - & - \\
\hline S_EPICA+ & $81 \pm 11$ & $-\mathrm{b}$ & - & - & - \\
\hline S_LR04 & $\mathbf{7 0} \pm 18$ & $51 \pm 12$ & 72 & $31 \pm 11$ & 44 \\
\hline S_IRON & $70 \pm 19$ & $50 \pm 10$ & 72 & $34 \pm 12$ & 49 \\
\hline S_NHICE & $68 \pm 19$ & $48 \pm 11$ & 70 & $29 \pm 10$ & 42 \\
\hline S_REGOLITH & $68 \pm 19$ & $48 \pm 11$ & 70 & $26 \pm 9$ & 39 \\
\hline S_COM & $70 \pm 18$ & $50 \pm 10$ & 72 & $32 \pm 11$ & 45 \\
\hline S_SO & $70 \pm 18$ & $54 \pm 14$ & 76 & $40 \pm 16$ & 56 \\
\hline S_FINAL & $70 \pm 18$ & $57 \pm 8$ & 81 & $48 \pm 11$ & 69 \\
\hline \multicolumn{6}{|c|}{ deep Pacific $\delta^{13} \mathrm{C}(\% o)$} \\
\hline ODP846 (1.8 Myr) & $0.49 \pm 0.12$ & $0.42 \pm 0.17$ & 86 & $0.41 \pm 0.15$ & 83 \\
\hline ODP677 (1.3 Myr) & $0.69 \pm 0.09$ & $0.57 \pm 0.18$ & 82 & $0.39 \pm 0.30^{\mathrm{c}}$ & 56 \\
\hline ODP677/846 & $0.55 \pm 0.03$ & $0.44 \pm 0.15$ & 80 & $0.40 \pm 0.16$ & 72 \\
\hline S_EPICA & $0.54 \pm 0.07$ & $-\mathrm{b}$ & - & - & - \\
\hline S_EPICA+ & $0.48 \pm 0.07$ & $-\mathrm{b}$ & - & - & - \\
\hline S_LR04 & $0.43 \pm 0.12$ & $\mathbf{0 . 3 1} \pm \mathbf{0 . 0 8}$ & 72 & $\mathbf{0 . 1 7} \pm \mathbf{0 . 0 5}$ & 39 \\
\hline S_IRON & $0.43 \pm 0.12$ & $0.32 \pm 0.07$ & 73 & $0.19 \pm 0.06$ & 44 \\
\hline S_NHICE & $0.43 \pm 0.13$ & $0.30 \pm 0.08$ & 71 & $0.17 \pm 0.05$ & 40 \\
\hline S_REGOLITH & $0.43 \pm 0.13$ & $0.30 \pm 0.08$ & 71 & $0.17 \pm 0.05$ & 39 \\
\hline S_COM & $0.44 \pm 0.12$ & $0.32 \pm 0.07$ & 73 & $0.19 \pm 0.06$ & 44 \\
\hline S_SO & $0.43 \pm 0.12$ & $0.33 \pm 0.08$ & 78 & $0.22 \pm 0.07$ & 51 \\
\hline S_FINAL & $0.44 \pm 0.12$ & $\mathbf{0 . 3 7} \pm \mathbf{0 . 0 5}$ & 84 & $\mathbf{0 . 2 9} \pm \mathbf{0 . 0 7}$ & 66 \\
\hline
\end{tabular}

${ }^{\text {a }}$ Variability of ice core $p \mathrm{CO}_{2}$ in the MPT contains only three $\mathrm{G} / \mathrm{IG}$ transitions.

$\mathrm{b}$ Results of S_EPICA, S_EPICA+ are restricted to $740 \mathrm{kyr}$ and are therefore omitted here.

${ }^{c}$ Variability of ODP677 in the $40 \mathrm{k}$ world contains only two G/IG transitions.

tation of $\delta^{13} \mathrm{C}$ in the Atlantic Ocean (scenario S_EPICA+). The results of both scenarios in terms of atmospheric $p \mathrm{CO}_{2}$ and deep Pacific $\delta^{13} \mathrm{C}$ are very similar (Fig. 7). Atmospheric $p \mathrm{CO}_{2}$ in $\mathrm{S} \_$EPICA agrees very well with the ice core measurements $\left(r^{2} \approx 0.75\right)$. Simulated $p \mathrm{CO}_{2}$ in S_EPICA+ is about $10 \mu \mathrm{atm}$ lower during glacial maxima than in S_EPICA. The simulated deep Pacific $\delta^{13} \mathrm{C}$ have G/IG amplitudes in the $100 \mathrm{k}$ world $(0.54 \%$ and $0.48 \%$ o for S_EPICA and S_EPICA+, respectively) which agree within their standard deviations with the data-based reconstruction (Table 4).

The approach solely based on the benthic $\delta^{18} \mathrm{O}$ stack (S_LR04) leads to atmospheric $p \mathrm{CO}_{2}$ which is remarkable similar to S_EPICA+. Results of S_LR04 underestimate $p \mathrm{CO}_{2}$ during interglacial periods by $10 \mu \mathrm{atm}$ with respect to S_EPICA+. The original simulations were already failing to reproduce the ice core measurements during these times by about $20 \mu \mathrm{atm}$. This offset is probably based on synchronisation deficits of the individual forcings and neglecting of details on coral reef growth during sea level high stands (Köhler and Fischer, 2006). These biases are less pronounced for the interglacials prior to $400 \mathrm{kyr} \mathrm{BP}$, for which in the ice cores only moderate atmospheric $p \mathrm{CO}_{2}$ values of 250 to $260 \mu \mathrm{atm}$ are found. During certain short $(<10 \mathrm{kyr})$ time windows the offset between $p \mathrm{CO}_{2}$ in $\mathrm{S} \_$LR04 and both the other scenarios 


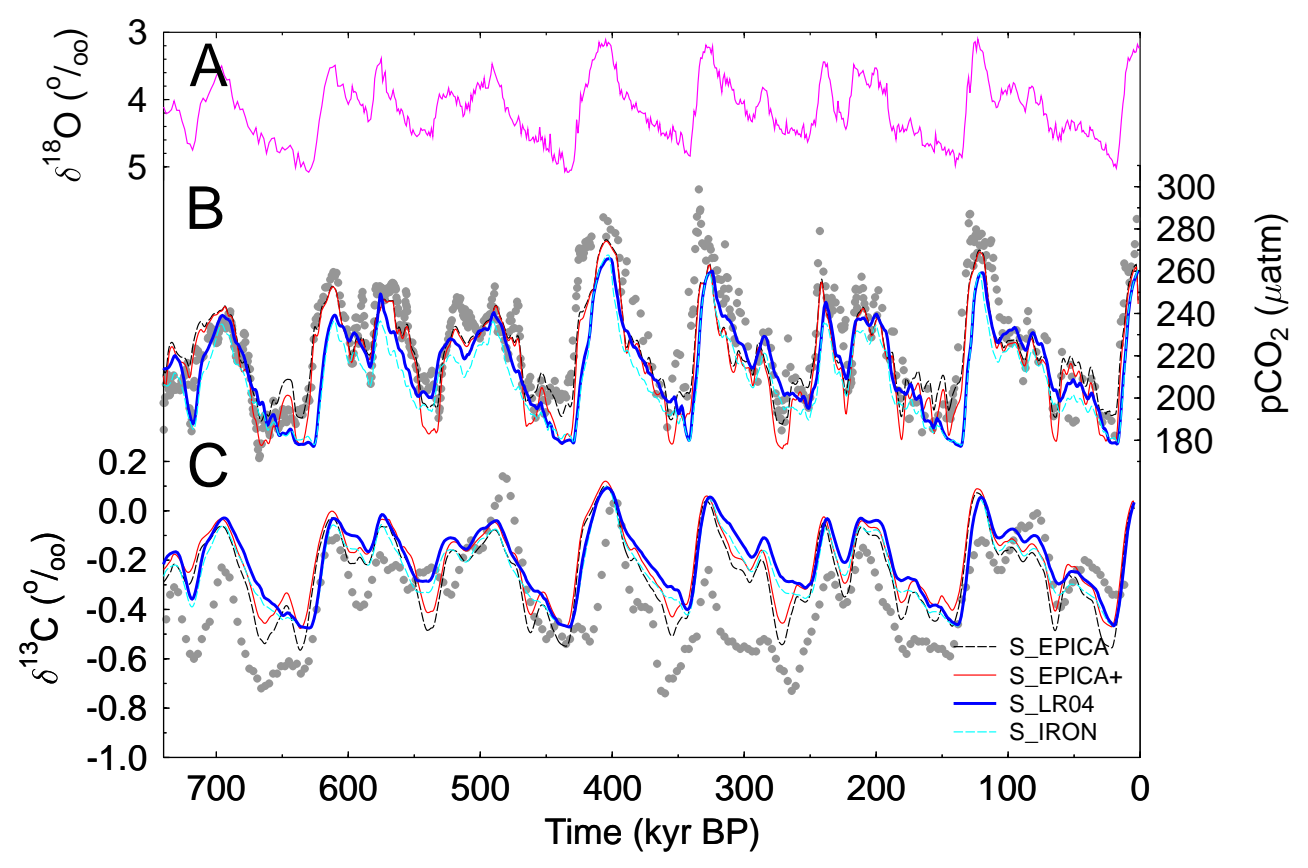

Fig. 7. Ground-truthing the simplified forcing approach based on LR04 (comparing it with other scenarios). (A) Stacked benthic $\delta^{18} \mathrm{O}$ (LR04) for comparison. (B) Simulated and measured (grey) $p \mathrm{CO}_{2}$. (C) Simulated and measured (grey) $\delta^{13} \mathrm{C}$ in the deep Pacific Ocean. Scenarios are described in Table 2. Data sets as described in Fig. 1.

and the data sets is larger (e.g. $60,170,270 \mathrm{kyr} \mathrm{BP}$ ). These periods were identified to be dominated by an enhanced marine export production (Köhler and Fischer, 2006). As mentioned earlier the correlation between the iron flux to Antarctica (which drives enhanced export production in the Southern Ocean via iron fertilisation) and LR04 is with $r^{2}=53 \%$ rather poor. Furthermore, the iron flux measured in EPICA Dome $\mathrm{C}$ varies over two orders of magnitude. Especially the occurrence and amplitude of peak maxima, which are most important for the marine export production, differs rather strongly between the original ice core data set and its LR04based surrogate (Fig. 3I). It is therefore not surprising to find that consequences of this process are not depicted very accurately within S_LR04. Results agree slightly better for the scenario S_IRON, which uses an alternative regression function between the iron flux and LR04 focused on changes during peaks in the iron flux.

For deep Pacific $\delta^{13} \mathrm{C}$ the offset between the scenario S_EPICA+ and S_LR04 is smaller than for atmospheric $p \mathrm{CO}_{2}\left(\delta^{13} \mathrm{C}: r^{2}=0.75 ; p \mathrm{CO}_{2}: r^{2}=0.62\right)$. Especially, there is no systematic bias in $\delta^{13} \mathrm{C}$ during the last five interglacials as seen in $p \mathrm{CO}_{2}$, however a point-to-point comparison of simulation and reconstruction is due to the missing $500 \mathrm{kyr}$ periodicity in the simulations difficult (see next section for details on this). The disagreements caused by the forcing of the marine export production during short time windows mentioned above is also clearly seen here. The G/IG amplitude in $\delta^{13} \mathrm{C}$ in the $100 \mathrm{k}$ world reaches with $0.43 \%$ o for both
S_LR04 and S_IRON about $80 \%$ and $90 \%$ of what is seen in the ODP cores and the simulation forced with the original paleo records (S_EPICA+), respectively.

To summarise, our simulation approach based on a simplified forcing of the model with LR04 leads to carbon cycle dynamics which are very similar to the results achieved with the model if forced with the original data sets. About 10\% of the $\mathrm{G} / \mathrm{IG}$ amplitudes in both atmospheric $p \mathrm{CO}_{2}$ and deep ocean $\delta^{13} \mathrm{C}$ are lost through this simplification. Fast features operating on time scales below $10 \mathrm{kyr}$ are not believed to be represented accurately with the LR04-based approach.

\subsection{The Null Hypothesis for the MPT}

We take the comparison presented in the previous subsection as evidence that the general model behaviour based on the simplified forcing approach is in the $100 \mathrm{k}$ world comparable with observations. Therefore, we first test the Null Hypothesis (scenario S_LR04: climate is similarly related to LR04 before and after the MPT) to interpret the MPT. This implies that no additional processes need to be considered for the interpretation of the carbon cycle during its transition from the $40 \mathrm{k}$ to the $100 \mathrm{k}$ world.

The G/IG amplitudes in atmospheric $p \mathrm{CO}_{2}$ are with on average $31 \pm 11 \mu \mathrm{atm}(40 \mathrm{k})$ and $51 \pm 12 \mu \mathrm{atm}$ (MPT) much smaller during earlier times than in the $100 \mathrm{k}$ period (70 $\pm 18 \mu \mathrm{atm})$. In the $40 \mathrm{k}$ world $p \mathrm{CO}_{2}$ varies only between $\sim 220$ and $\sim 260 \mu \mathrm{atm}$. These amplitudes are rather small, 


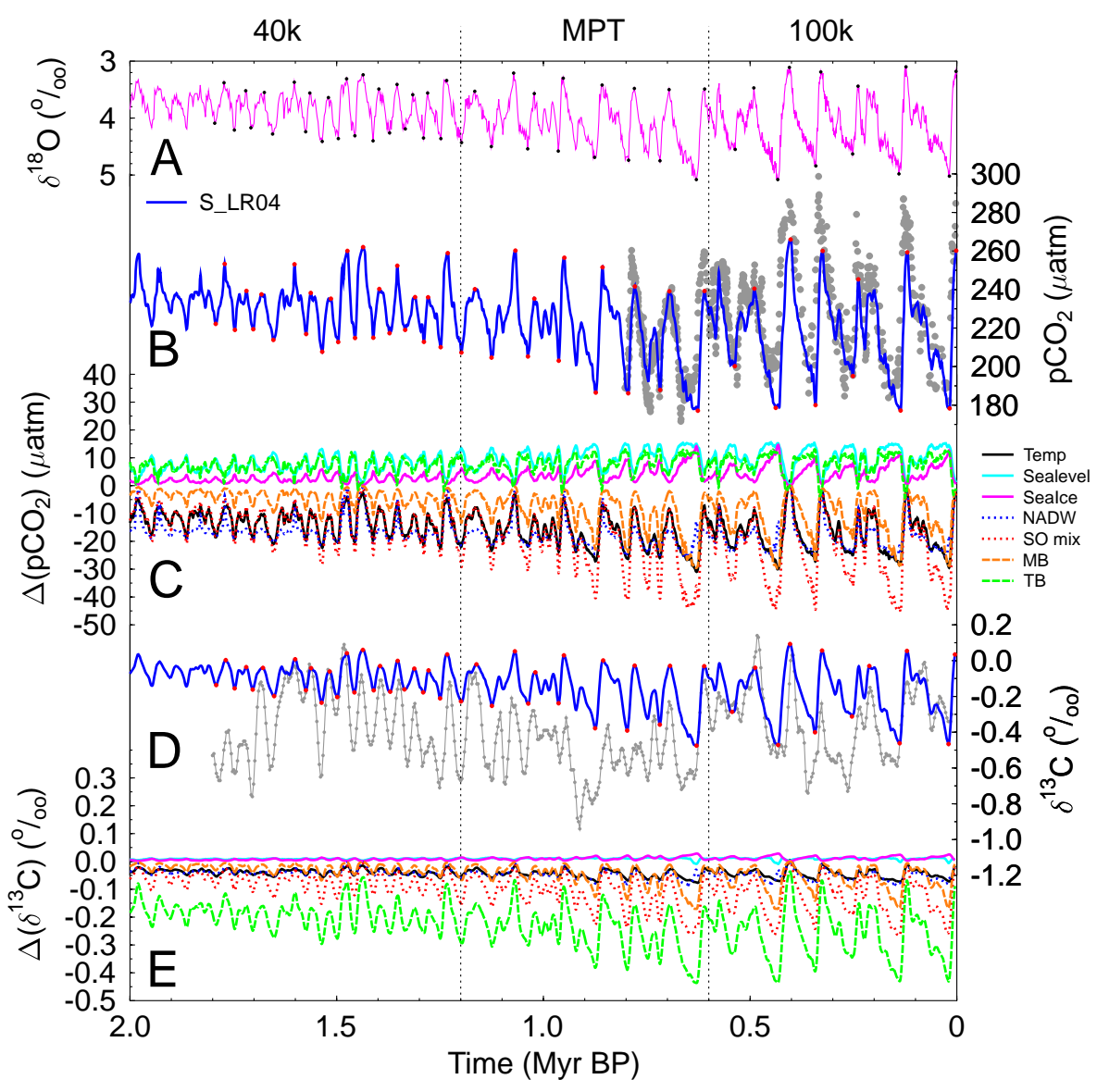

Fig. 8. Simulation results of the Null Hypothesis (scenarios S_LR04). (A) Stacked benthic $\delta^{18}$ O (LR04) for comparison. (B) Simulated and measured (grey) $p \mathrm{CO}_{2}$. (D) Simulated and measured (grey) $\delta^{13} \mathrm{C}$ in the deep Pacific Ocean. (C), (E) Contribution of individual processes to changes in $p \mathrm{CO}_{2}(\mathrm{C})$ and deep Pacific $\delta^{13} \mathrm{C}(\mathrm{E})$. The observed processes include changes in ocean temperature (Temp), sea level (Sealevel), gas exchange through sea ice cover (SeaIce), North Atlantic deep water formation (NADW), vertical mixing in the Southern Ocean (SO mix), marine biology due to iron fertilisation of the Southern Ocean (MB) and terrestrial carbon storage (TB). Data sets as described in Fig. 1. Red dots in (B, D) denote local minima/maxima within individual MIS, which were used to calculate G/IG amplitudes.

but we have to consider the known reduction of the G/IG amplitudes of $10 \%$ caused by our simplified LR04-based forcing. The relative size of the $\mathrm{G} / \mathrm{IG}$ amplitudes in $p \mathrm{CO}_{2}$ in the $40 \mathrm{k}$ world is $44 \%$ of that in the $100 \mathrm{k}$ world. This is smaller than the reduction in the G/IG amplitudes of the climate signal $\left(f_{40 \mathrm{k}}=51 \%\right)$ recorded in LR04 (Table 4$)$.

Similarly, the amplitudes in deep Pacific $\delta^{13} \mathrm{C}$ during the MPT are in scenario SLR04 further reduced than in the $\delta^{13} \mathrm{C}$ data set (Table 4). In the $40 \mathrm{k}$ world they are reduced to only $39 \%$ of their $100 \mathrm{k}$ world values, which is about half of the relative size given in the data set $(72 \%)$, and also smaller than the reduction in the LR04 climate signal (51\%). The increase in $\mathrm{G} / \mathrm{IG}$ amplitude over time in the reconstructions from $0.40 \%$ o $(40 \mathrm{k})$ to $0.55 \%$ o $(100 \mathrm{k})$ is not negligible, indicating already to some changes in the carbon cycle. However, this change is reduced by a factor two if only data from ODP846 are considered and are furthermore in the range of the standard deviation (Table 4). A conservative interpretation of the data might therefore argue for more or less stable G/IG amplitude in deep Pacific $\delta^{13} \mathrm{C}$ over time. Results of the Null Hypothesis, however, show a rise in G/IG amplitudes by $150 \%$ (from $0.17 \%$ o ( $40 \mathrm{k}$ ) to $0.43 \%$ o (100 k)). Based on this disagreement in deep ocean $\delta^{13} \mathrm{C}$ (see also time series in Fig. 8D) we have to reject our Null Hypothesis (climate is similarly related to LR04 before and after the MPT) to explain the observed variations in the carbon cycle over the MPT. Furthermore, this implies that even the conservative data interpretation (stable G/IG amplitudes over time) asks in the contexts of changing climate as depicted by LR04 for an additional process connected with the MPT, which prevents the carbon cycle from changing.

A spectral analysis (not shown) of the simulated deep Pacific $\delta^{13} \mathrm{C}$ finds orbital frequencies of about 20, 40, and $100 \mathrm{kyr}$ in the simulation results, similar as in the paleo 


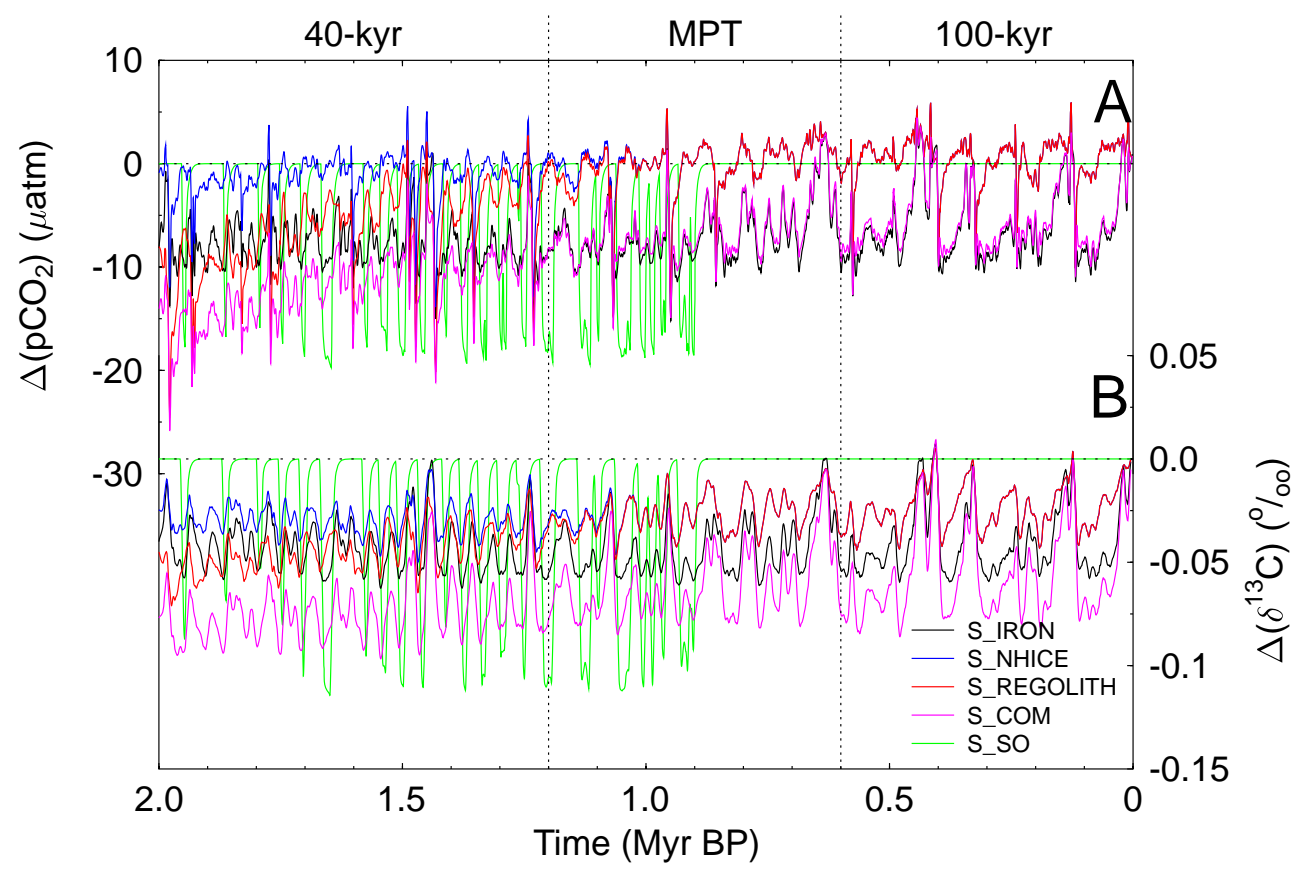

Fig. 9. Difference between S_LR04 and alternative scenarios for (A) atmospheric $p \mathrm{CO}_{2}$ and (B) deep Pacific $\delta^{13} \mathrm{C}$. Scenarios are described in Table 2.

record, but does not find any power in the low frequency component of $\sim 1 / 400-1 / 500 \mathrm{kyr}^{-1}$. This holds for S_LR04 and all other scenarios discussed below. This discrepancy in the power spectra between model results and reconstruction can be explained if one follows a recent hypothesis on the explanation of the observed $\sim 500 \mathrm{kyr}$ cycle in benthic $\delta^{13} \mathrm{C}$. According to Wang (2007) it is based on the variability of the monsoon and its long-term impacts on continental weathering and riverine input of bicarbonate into the world ocean and thus the carbon cycle via the hydrological cycle. Because the latter is not included in BICYCLE data and model are expected to disagree in this frequency domain.

The contribution of individual processes to both the variations in atmospheric $p \mathrm{CO}_{2}$ and deep Pacific $\delta^{13} \mathrm{C}$ are identified through a factorial analysis. For this analysis the differences in both variables between the control run (S_LR04) and simulations in which the one process in question is passive are calculated (Fig. 8C, E). The considered processes here are changes in ocean temperature, sea level, gas exchange rate via sea ice cover, the strength of the Atlantic meridional overturning represented by the NADW formation, vertical mixing and iron fertilisation of the marine biology in the Southern Ocean, and terrestrial carbon storage. $\mathrm{CaCO}_{3}$ compensation is active in the whole analysis and the contributions of the individual processes therefore include the partial effect of the sediment/ocean interaction. Processes are thus called to be "equilibrated with the sediments". This factorial analysis is a first order estimate of individual contributions which neglects nonlinear interacting effects. Some interesting de- tails can be learnt from this analysis: the variability in deep Pacific $\delta^{13} \mathrm{C}$ is dominated by changes in terrestrial carbon storage, Southern Ocean vertical mixing and to a certain extent marine productivity. All these three processes contribute to $\mathrm{G} / \mathrm{IG}$ amplitudes in deep Pacific $\delta^{13} \mathrm{C}$ which are larger in the Early than in the Late Pleistocene. Furthermore, the contribution of Southern Ocean processes (vertical mixing and marine export production) to $\mathrm{G} / \mathrm{IG}$ amplitudes in both variables $\left(p \mathrm{CO}_{2}, \delta^{13} \mathrm{C}\right)$ was clearly reduced prior to the MPT (Fig. 8C, E). If one seeks a theory which brings simulations of deep Pacific $\delta^{13} \mathrm{C}$ in better agreement with the reconstructions one might need to revise the temporal changes in one of these processes in the model.

\subsection{Alternative scenarios supported by independent evi-} dences

To perform better than our Null Hypothesis alternative scenarios have to produce especially larger $\mathrm{G} / \mathrm{IG}$ amplitudes in deep Pacific $\delta^{13} \mathrm{C}$ before the MPT. Due to the missing $p \mathrm{CO}_{2}$ reconstructions in the $40 \mathrm{k}$ world, the performance of simulated atmospheric $p \mathrm{CO}_{2}$ is difficult to assess. Differences between the alternative scenarios and the Null Hypothesis (S_LR04) are summarised in Fig. 9.

Enhanced marine export production: If the alternative forcing of aeolian iron flux to Antarctica/Southern Ocean is used (S_IRON) only small differences to S_LR04 of up to $10 \mu \mathrm{atm}$ in $p \mathrm{CO}_{2}$ and of $0.05 \%$ and Pacific $\delta^{13} \mathrm{C}$ are found throughout the simulation period. The relative size of the 
$\mathrm{G} / \mathrm{IG}$ amplitudes in the $40 \mathrm{k}$ in comparison to the $100 \mathrm{k}$ world are slightly increased to $49 \%$ and $44 \%$ for $p \mathrm{CO}_{2}$ and $\delta^{13} \mathrm{C}$, respectively. The discrepancy between simulated and reconstructed oceanic $\delta^{13} \mathrm{C}$ is still too large to assess S_IRON as an acceptable scenario.

Northern Hemisphere glaciation: The differences of the Null Hypothesis and scenario S_NHICE, which implicitly assumes that changes in sea level are mainly caused by northern hemispheric ice sheets, are with $<5 \mu$ atm for $p \mathrm{CO}_{2}$ and $\sim 0.05 \%$ o and Pacific $\delta^{13} \mathrm{C}$ small. $f$-ratios are with $42 \%$ $\left(p \mathrm{CO}_{2}\right)$ and $40 \%\left(\delta^{13} \mathrm{C}\right)$ in the $40 \mathrm{k}$ world very similar to those of the LR04-based scenario.

Effect of regolith erosion: Additionally to S_NHICE, the effect of ongoing silicate weathering input through the erosion of the regolith layer beneath the northern hemispheric ice sheets was investigated in S_REGOLITH. The additional and gradually declining input of bicarbonate into the ocean via silicate weathering between 2 and $1 \mathrm{Myr} \mathrm{BP}$ (Fig. 3F) leads to a long-term increase in $p \mathrm{CO}_{2}$ of about $10 \mu \mathrm{atm}$ during the same period of time if compared with S_LR04. This is consistent with other carbon cycle models on chemical weathering (Munhoven, 2002): Higher silicate weathering rates imply a drop in atmospheric $p \mathrm{CO}_{2}$, because not only DIC but also alkalinity in the ocean is changed by the riverine input of bicarbonate. Again, results are very similar to the Null Hypothesis with slightly smaller $f$-ratios in the $40 \mathrm{k}$ world.

Combining all above: Even if we combine these three alternatives (scenario S_COM), the results are still not improving in a way which leads to $\mathrm{G} / \mathrm{IG}$ amplitudes in the $40 \mathrm{k}$ world $\left(f_{40 \mathrm{k}}\left(\delta^{13} \mathrm{C}\right)=44 \%\right)$ which are in the range seen in the data sets.

We can therefore summarise, that the improvements achieved through alternative scenarios well supported by other studies are with respect to the simulated G/IG amplitudes in deep Pacific $\delta^{13} \mathrm{C}$ in the $40 \mathrm{k}$ world inadequate. None of the alternatives, which are based on either revised forcings due to known weak representation in the Null Hypothesis approach (S_IRON), or on additional evidences how the carbon cycle might have changed during the MPT (S_NHICE, S_REGOLITH), nor a combination of all (S_COM) leads anywhere near the reconstructed variability. We therefore will in the following revise some of our assumptions, in order to suggest another scenario, whose results are in better agreement with the paleo data set.

\subsection{The Southern Ocean Decoupling Hypothesis}

One main reason for the use of the LR04-based forcing approach (our Null Hypothesis) is a lack of Antarctic ice core records, which represent Southern Ocean climate, extending $2 \mathrm{Myr}$ back in time. However, there are good reasons to believe, that the extrapolation of LR04-based forcing of SST changes in the Southern Ocean to the $40 \mathrm{k}$ world are reasonable, as reconstructed planktic $\delta^{18} \mathrm{O}$ and summer SST (Bec- quey and Gersonde, 2002; Venz and Hodell, 2002) indicate independently and similar to our approach that G/IG amplitudes in SST in the Southern Ocean might have been smaller prior to the MPT (see EPICA Dome C $\delta \mathrm{D}$ and and substitute in Fig. 3H, which are taken as proxy for Southern Ocean SST). This has in BICYCLE direct consequences for Southern Ocean deep mixing which is a function of SST.

The factorial analysis of the contribution of individual processes to changes in atmospheric $p \mathrm{CO}_{2}$ and deep Pacific $\delta^{13} \mathrm{C}$ (Sect. 3.3, Fig. 8C, E) has shown, that especially the $\mathrm{G} / \mathrm{IG}$ amplitudes of processes situated in the Southern Ocean differ largely between the $40 \mathrm{k}$ and the $100 \mathrm{k}$ world. Furthermore, these processes have the largest potential, if revised, to bring simulated deep Pacific $\delta^{13} \mathrm{C}$ in closer agreement to the reconstructions before the MPT. Based on this understanding and the evidences on smaller Southern Ocean SST given above, we suggest, that before the MPT changes in the Southern Ocean vertical mixing rates were decoupled from changes in SST and thus from the global climate change recorded in LR04. This Southern Ocean Decoupling Hypothesis primarily focuses on ocean circulation, but a decoupling of other Southern Ocean processes (e.g. marine export production) from global climate is thinkable. An alternative development of this idea of a decoupling in the Southern Ocean might be that the functional relationship between Southern Ocean SST and the oceanic mixing rates is kept unchanged, but that Southern Ocean SST before the MPT cannot be extrapolated with linear regression functions out of LR04. This might be motivated with the large uncertainty in the G/IG amplitudes in Southern Ocean SST published so far (e.g. Becquey and Gersonde, 2002; Venz and Hodell, 2002). However, this alternative is not developed any further in the following.

The decoupling in the Southern Ocean is proposed because of the impossibility of our carbon cycle model to generate $\mathrm{G} / \mathrm{IG}$ amplitudes in the $40 \mathrm{k}$ world in deep Pacific $\delta^{13} \mathrm{C}$ which are comparable with data sets, however first evidences of a different behaviour of the carbon cycle and the climate system emerged already from the analysis of G/IG amplitudes of LR04 and $\delta^{13} \mathrm{C}$ (Table 4). So far, we have no in-depth idea how the decoupling might operate based on physical principles, but some first estimates how it can be implemented in our carbon cycle model are described in this section and potential physical mechanisms are discussed in Sect. 4. For the time being, we therefore implement in an additional scenario (S_SO) a functional relationship between the Southern Ocean SST surrogate and vertical mixing rates, in which Southern Ocean stratification during glacials is largely enhanced before $900 \mathrm{kyr}$ BP (see Table 3 for details, Fig. 4C). The time for switching this decoupling off was arbitrarily chosen to be exactly the middle of our MPT time window. Other times or a gradually transitions are certainly thinkable. As long as we do not have evidences how this decoupling might operate from first principles we have to acknowledge that this approach here is mainly a first suggestion. 


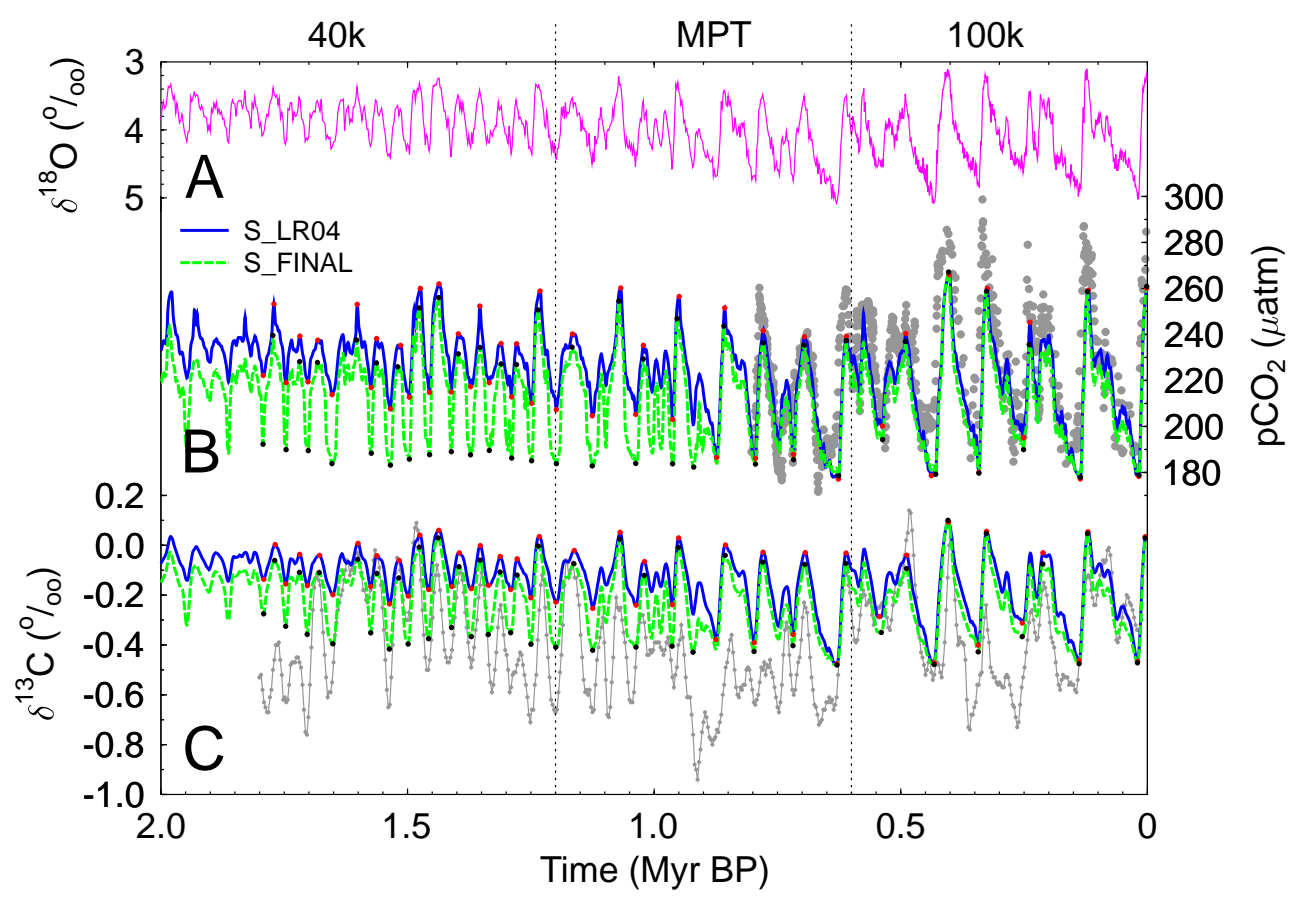

Fig. 10. Results for our the Null Hypothesis (S_LR04) and our best guess scenario (S_FINAL). (A) Stacked benthic $\delta^{18}$ O (LR04). (B) Simulated and measured (grey) $p \mathrm{CO}_{2}$. (C) Simulated and measured (grey) $\delta^{13} \mathrm{C}$ in the deep Pacific Ocean. Data sets as described in Fig. 1. Red and black dots in (B, C) denote local minima/maxima within individual MIS, which were used to calculate G/IG amplitudes.

If the Southern Ocean mixing/stratification is revised as suggested (scenario S_SO), the carbon cycle variability in the MPT and the $40 \mathrm{k}$ world becomes substantially larger by $\sim 20 \mu \mathrm{atm}$ and $0.12 \%$ (Fig. 9). The $f$-ratios increase to $78 \%$ and $51 \%$ for $\delta^{13} \mathrm{C}$ and $76 \%$ and $56 \%$ for $p \mathrm{CO}_{2}$ for the MPT and the $40 \mathrm{k}$, respectively. Combining the Southern Ocean Decoupling Hypothesis with all other improvements (scenario S_FINAL) leads to further increases in the $f$-ratios to $84 \%$ and $66 \%\left(\delta^{13} \mathrm{C}\right.$ : MPT or $40 \mathrm{k}$, respectively) and $81 \%$ and $69 \%$ ( $p \mathrm{CO}_{2}$ : MPT or $40 \mathrm{k}$, respectively). Thus, especially the relative changes in the G/IG amplitudes in deep Pacific $\delta^{13} \mathrm{C}$ are now very close to those detected in the ODP records in the MPT (80\%) and the $40 \mathrm{k}$ world $(72 \%)$. In S_FINAL atmospheric $p \mathrm{CO}_{2}$ varies between $\sim 180$ and $\sim 260 \mu \mathrm{atm}$ throughout the $40 \mathrm{k}$ world and the MPT (Fig. 10B). This range is similar to the $\mathrm{CO}_{2} \mathrm{ob}-$ servations measured in EPICA Dome $\mathrm{C}$ between 450 and $800 \mathrm{kyr}$ BP (Siegenthaler et al., 2005; Lüthi et al., 2008), although the absolute minimum in the ice core data set drops to 170 ppmv in MIS 16. Pacific $\delta^{13} \mathrm{C}$ is approximately limited to variations between $0.0 \%$ and $-0.4 \%$ (Fig. 10C).

Altogether, we can summarise that the Southern Ocean Decoupling Hypothesis together with other improvements of our LR04-based approach leads to simulation results, which are in their relative changes in the G/IG amplitudes in deep Pacific $\delta^{13} \mathrm{C}$ comparable with the reconstructions from two ODP records in the equatorial Pacific. So far, simu- lated $p \mathrm{CO}_{2}$ before the MPT varies between 180-260 $\mu \mathrm{atm}$ (Fig. 10). Although these values are a first guess of the variability of atmospheric $\mathrm{CO}_{2}$ in the $40 \mathrm{k}$ world, they need to be confirmed with either ice core data sets or reconstructions based on oceanic proxies, before they can be taken as reliable. For this comparison of simulation results with paleo reconstructions one has to keep in mind the $10 \%$ reduction in $\mathrm{G} / \mathrm{IG}$ amplitudes of both atmospheric $p \mathrm{CO}_{2}$ and deep Pacific $\delta^{13} \mathrm{C}$ caused by the LR04-based forcing approach.

\section{Discussions and conclusions}

This study focuses on the understanding of G/IG dynamics in the carbon cycle before, during, and after the MPT. For this aim, simulation results of atmospheric $p \mathrm{CO}_{2}$ and deep Pacific $\delta^{13} \mathrm{C}$ achieved with the carbon cycle box model BICYCLE are compared with reconstructions from sediment and ice cores.

We find that a Null Hypothesis in which climatic changes are mainly represented by the LR04 benthic $\delta^{18} \mathrm{O}$ stack cannot explain the reduced G/IG amplitudes in Pacific benthic $\delta^{13} \mathrm{C}$ in the $40 \mathrm{k}$ world. This Null Hypothesis leads to reasonable simulation results in both atmospheric $p \mathrm{CO}_{2}$ and deep Pacific $\delta^{13} \mathrm{C}$ in the $100 \mathrm{k}$ world, in which an independent validation with more complex forced simulations and atmospheric $\mathrm{CO}_{2}$ data from ice cores is possible. We used this 
validation as ground-truthing of the Null Hypothesis, which gave us reasons to believe, that our assumptions might already be sufficient for the interpretation of the carbon cycle during the last $2 \mathrm{Myr}$. However, even with improvements of our Null Hypothesis with evidences based on other theories the simulated $\mathrm{G} / \mathrm{IG}$ amplitudes in deep Pacific $\delta^{13} \mathrm{C}$ are not in agreement with data-based reconstructions. Only if we revise the functional relationship between water column stratification and SST in the Southern Ocean, what we call the Southern Ocean Decoupling Hypothesis, the G/IG amplitudes found in benthic $\delta^{13} \mathrm{C}$ in the Pacific Ocean can be matched with our simulation results.

This failure of the Null Hypothesis is remarkable. First evidences for the decoupling of climate and the carbon cycle can already be gained from a comparison of the relative sizes of the G/IG amplitudes before and after the MPT of the paleo records LR04 and benthic $\delta^{13} \mathrm{C}$ (Table 4). The way how the G/IG amplitudes evolved differently over the MPT in both records (increase by $100 \%$ and $40 \%$ in LR04 and benthic $\delta^{13} \mathrm{C}$, respectively) is a first hind at different dynamics in the climate system and the carbon cycle. Thus, this first evidence of a decoupling is independent of the used carbon cycle model and therefore needs to be addressed to understand the dynamics of the Earth during the MPT regardless of our model-based Southern Ocean Decoupling Hypothesis. It was furthermore surprising to find in the simulation results of our Null Hypothesis (S_LR04) that in the $40 \mathrm{k}$ world the $f$-ratio in $\delta^{13} \mathrm{C}$ was even smaller than in LR04, thus opposite than in the data sets.

The proposed Southern Ocean Decoupling Hypothesis is additive and not mutually exclusive to those simulations which are based on other theories and which were already combined in one of our scenarios (S_COM). So far, it seems that where climate evolution over the MPT is of interest, published hypotheses do not consider similar processes as the Southern Ocean decoupling proposed here. Only if the carbon cycle becomes in focus further assumptions on temporal changes have to be considered. From our model-based understanding we believe that the Southern Ocean is a key area also for the interpretation of carbon cycle dynamics over the MPT, as it has already been identified to be a major player for atmospheric $\mathrm{CO}_{2}$ during G/IG dynamics (e.g. Stephens and Keeling, 2000; Watson and Naveira-Garabato, 2006) and for recent and future uptake of anthropogenic carbon emissions (e.g. Le Quéré et al., 2007; Lovenduski et al., 2007). However, we have to acknowledge that our understanding of the climate and the carbon cycle in the Southern Ocean is incomplete and sometimes contradictory (Toggweiler et al., 2006; Tschumi et al., 2008). In this respect, we argue that those additional information hidden in the proxies of the carbon cycle need more attention and can be used to sharpen theories on climate evolution.
The sensitivity of carbon cycle box models and continuum models was compared in various studies (e.g. Broecker et al., 1999; Archer et al., 2000). It was shown that box models tend to be more sensitive to changes in the high-latitudes than continuum models. Although, this behaviour is especially pronounced in models with three oceanic boxes (Knox and B.McElroy, 1984; Sarmiento and Toggweiler, 1984; Siegenthaler and Wenk, 1984), it is also manifested in box models with higher resolution, such as BICYCLE (10 ocean boxes). Note, that BICYCLE's sensitivity to low-latitude changes is in the range of GCMs (for more details see Köhler et al., 2005). Recently, the conclusions of these earlier studies were brought into question. Marinov et al. (2008) analysed in detail how ocean biology affect atmospheric $p \mathrm{CO}_{2}$. They contradict the findings of Archer et al. (2000) and show that one must be extremely careful when comparing different models and when designing comparison indices. According to Marinov et al. (2008) preformed nutrient concentrations are most important for marine biology and for atmospheric $p \mathrm{CO}_{2}$. Small differences in ocean circulation might lead via consequently different preformed nutrient concentrations to large differences in the sensitivity of $p \mathrm{CO}_{2}$ to high-latitude forcing.

In this respect it is difficult to judge if or how much of our Southern Ocean Decoupling Hypothesis is dependent on the box model architecture of BICYCLE. The detailed model response is to a certain degree model dependent, as in every simulation experiment, even with more complex models. Various model-intercomparison project have shown that even models of similar complexity behave differently, e.g. the 11 carbon cycle-climate models of the $\mathrm{C}^{4} \mathrm{MIP}$ intercomparison calculated atmospheric $\mathrm{CO}_{2}$ values at the end of this century ranging between 730 and 1020 ppmv (Friedlingstein et al., 2006). However, more complex models are still not available for the investigations on these long time scales and box models are therefore state-of-the-art for these long integrations.

What independent evidences or alternative theories do we have to support our Southern Ocean Decoupling Hypothesis? Most approaches on the interpretation of the MPT published so far are concentrating on changes in the Northern Hemisphere (e.g. Clark et al., 2007; Bintanja and van de Wal, 2008), although the approach of Bintanja and van de Wal (2008) already considers a 15\% contribution of global sea level change from Greenland and Antarctic ice sheets (Bintanja et al., 2002). Recently, Raymo et al. (2006) proposed that changes in climate and ice volume in both the Northern Hemisphere and Southern Hemisphere, each controlled by local summer insolation, need to be considered between 3 and $1 \mathrm{Myr}$ BP for the interpretation of the LR04 $\delta^{18} \mathrm{O}$ stack. During this time window Earth's orbital precession and thus midsummer insolation are out of phase between hemispheres. This implies that 20 -kyr changes in ice volume in each hemisphere cancel out in globally integrated proxies such as the oceanic $\delta^{18} \mathrm{O}$ or sea level leaving the inphase obliquity (40-kyr) component of insolation to domi- 

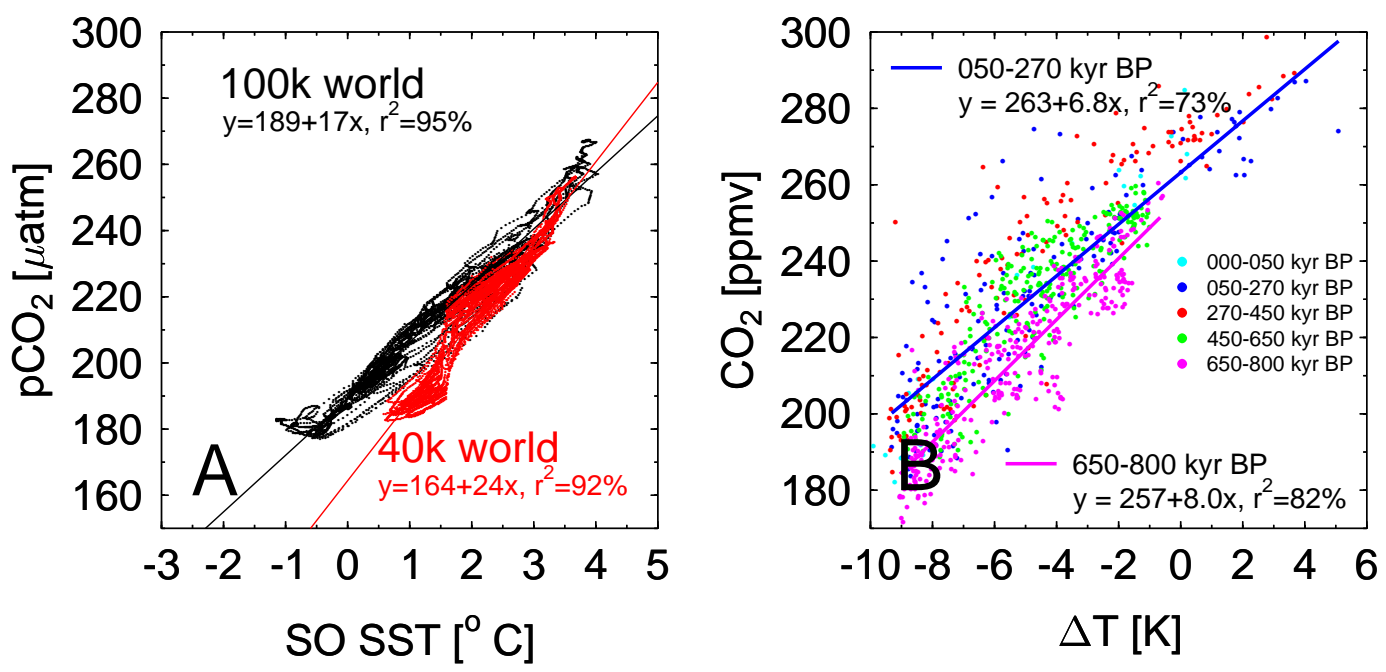

Fig. 11. (A): Correlation between Southern Ocean (SO) SST and atmospheric $p \mathrm{CO}_{2}$ in our best guess scenario S_FINAL. Data and linear regression for the time windows $40 \mathrm{k}$ world (1.8-1.2 Myr BP, red) and $100 \mathrm{k}$ world (0.6-0 Myr BP, black) are shown for comparison. (B): Correlation between Antarctic temperature anomaly $\triangle \mathrm{T}$ and atmospheric $\mathrm{CO}_{2}$ as measured in Vostok and EPICA Dome $\mathrm{C}$ ice cores. Vostok $\mathrm{CO}_{2}$ (Petit et al., 1999) on the orbital tuned age scale (Shackleton, 2000), EDC CO 2 (Siegenthaler et al., 2005; Lüthi et al., 2008) on the EDC3_gas_a age scale (Loulergue et al., 2007; Parrenin et al., 2007b), $\Delta$ T (Jouzel et al., 2007) on the EDC3 age scale (Parrenin et al., 2007a). $\mathrm{CO}_{2} / \Delta \mathrm{T}$ data are divided and colour-coded in time windows of two glacial cycles each as in Lüthi et al. (2008).

nate those records. They further hypothesised that before the MPT the extent of the East Antarctic Ice Sheet (EAIS) during interglacials was largely reduced due to higher temperatures. Furthermore, at the MPT marine-based ice sheet margins should have replaced terrestrial ice margins around the perimeter of East Antarctica, resulting in a shift to inphase behaviour of northern and southern ice volume. The consequence of this "EAIS hypothesis", that ice shelfs might shrink and disappear completely during G/IG cycles in the $40 \mathrm{k}$ world, would certainly have consequences for deep and bottom water formation rates, however, their magnitude is difficult to assess. Existing modelling (Hellmer, 2004) and data-based studies (e.g. Huhn et al., 2008), which focus on the Weddell Sea, highlight that changes in both the ice shelf area and melting at the base of the ice shelf would impact on sea ice and deep ocean properties. In detail, a reduction in both parameters would, according to Hellmer (2004), lead to a decrease in the stability of the water column, enhance deep convection and the formation of dense bottom water. It is difficult to estimate if and how changes in the ice shelf areas around the EAIS would lead to similar consequences. However, based on these studies it can be expected that large changes in Antarctic ice sheet volume and shelf ice extent (as proposed by Raymo et al., 2006) would also impact on ocean circulation. Accordingly, a decoupling of Southern Ocean circulation and SST seems to be a reasonable assumption for the climatic shifts connected with the MPT. The EAIS hypothesis would then imply impacts on Southern Ocean cir- culation in the $40 \mathrm{k}$ world with the periodicity of the precession (20-kyr). Related to this we cannot detect an increase in spectral power in this frequency band in the 40-kyr world (Fig. 6D-F).

Another theory which focuses on processes in the Southern Hemisphere is the "insolation canon hypothesis" of Schulz and Zeebe (2006). It also proposes a connection of the precession cycle and the occurrence of glacial terminations. They analysed the midsummer insolation at $65^{\circ} \mathrm{N}$ and $65^{\circ} \mathrm{S}$ over the last $2 \mathrm{Myr}$ (which both vary mainly with the 20-kyr of the precession) and argued that only when the insolation in both high latitudes increased simultaneously, led by the south, and contained a certain amount of energy a large $\mathrm{G} / \mathrm{IG}$ transition was triggered. This approach gives hints that insolation changes in both northern and southern high latitudes are important for triggering Terminations I-VII. Further back in time (before the MPT) the insolation regime change: The increase in midsummer insolation was not led by the south or the amount of energy supply corresponding to the insolation increase was smaller than after the MPT and less than a proposed energy threshold necessary for triggering a deglaciation. This is no direct evidence that and how climate in the southern high latitudes differed between Early and Late Pleistocene, but it indicates that the southern high latitudes played a different role during $\mathrm{G} / \mathrm{IG}$ transitions in the $40 \mathrm{k}$ and in the $100 \mathrm{k}$ world.

Our findings, especially the fact that a decoupling between climate and carbon cycle dynamics is seen in the LR04 $\delta^{18} \mathrm{O}$ 
and benthic $\delta^{13} \mathrm{C}$ data without the use of any model, suggests that a revised interpretation of the MPT is necessary, in which changes from the $40 \mathrm{k}$ to the $100 \mathrm{k}$ world in certain processes are required. This conclusion would imply that the interpretation of Huybers (2007) on the MPT might need some refinement. Huybers proposed that there might have been no major abrupt change in the climate system over the MPT. He argued that the glacial variability as seen in a $\delta^{18} \mathrm{O}$ stack dated independently from orbital forcing can be explained solely by the obliquity cycle given by a 40-kyr periodicity during the last $2 \mathrm{Myr}$. This hypothesis suggests that the glacial cycles were and are continuously governed by obliquity pacing, but that late Pleistocene glaciations repeatedly skip one or two obliquity cycles, thus resulting in 80 or $120 \mathrm{kyr}$ (on average 100 -kyr) periodicity. This would solve both the questions what drove the 100-kyr variability of the late Pleistocene and how the climate system shifted from the 40-kyr towards the 100-kyr variability during the MPT. However, if the decoupling of SST and vertical mixing in the Southern Ocean as proposed in our hypothesis occurred gradually over the last $2 \mathrm{Myr}$, and not as abrupt as assumed in our scenario S_SO, then our hypothesis would be in line with the interpretation of Huybers (2007).

We furthermore believe, that hypotheses which concentrate on the Northern Hemisphere glaciation as the dominant process for the interpretation of the MPT alone (Clark et al., 2007; Bintanja and van de Wal, 2008) are not sufficient to explain all the variability seen in various proxy records. They are from our point of view nevertheless valuable and important pieces in the jigsaw to understand the transition from the $40 \mathrm{k}$ to the $100 \mathrm{k}$ world.

We have to point out that due to the simplicity of our LR04-based forcing mechanism and the way we decoupled the Southern Ocean circulation and climate our results are interesting mainly with respect to their G/IG amplitudes. Further details, such as how atmospheric $p \mathrm{CO}_{2}$ varied in detail between 180 and $260 \mu$ atm are more difficult to assess due to missing $p \mathrm{CO}_{2}$ reconstructions in the pre-ice core time window. It has been suggested by various authors (e.g. Clark et al., 2007; Huybers, 2007) that the global cooling trend observed in LR04 might be caused by falling greenhouse gas concentrations. This suggestion is not supported for $p \mathrm{CO}_{2}$ from our study, but this might be a model-dependent response, based on the crude implementation of the Southern Ocean decoupling and the coarse representation of weathering fluxes and deep ocean $\mathrm{CaCO}_{3}$ chemistry (no processbased model of the sediments included).

Nevertheless, the effect of the Southern Ocean decoupling on atmospheric $p \mathrm{CO}_{2}$ would be that the high correlation of Antarctic temperature and atmospheric $p \mathrm{CO}_{2}$ found during the last $650 \mathrm{kyr}$ (Siegenthaler et al., 2005) is reduced and that a different relationship between both variables was established in the $40 \mathrm{k}$ world. This is clearly illustrated in the scatter plot of the Southern Ocean SST forcing and the simulated atmospheric $p \mathrm{CO}_{2}$ (Fig. 11A), where we find, that the slope between $p \mathrm{CO}_{2}$ and SST is increased in the $40 \mathrm{k}$ world. This means that the same anomaly in Southern Ocean SST would coincide with a larger amplitude in the $40 \mathrm{k}$ world compared to the $100 \mathrm{k}$ world. This trend is already seen if similar relationships are analysed in the ice core records for different time windows (Fig. 11B). If the relation between $\mathrm{CO}_{2}$ and Antarctic surface temperature anomaly $\Delta T$ are analysed, we also find steeper slopes further back in time. Although the differences in the slopes are rather small, they indicate to similar changes in the carbon cycle/climate system over the MPT than our Southern Ocean Decoupling Hypothesis.

In summary, our approach suggests that Southern Ocean climate and ocean circulation might be the variables to look at in the Early Pleistocene and across the MPT. Similar to Wang et al. (2004) we propose that the information contained in the carbon cycle needs to be addressed to get a full picture of Earth's climate variability.

Acknowledgements. We thank the organizers of the conference "Climate change: from the geologic past to the uncertain future: Atribute to André Berger, 26 to 29 May 2008, Louvain-la-Neuve University, Belgium" for giving $\mathrm{PK}$ the change to present the content of this paper on the conference. Hubertus Fischer, Bärbel Hönisch and Peter Huybers gave helpful remarks to earlier drafts. Dieter Lüthi provided $\mathrm{CO}_{2}$ data prior to publication, Torsten Bickert and Ed Boyle made their published $\delta^{13} \mathrm{C}$ data sets electronically available. Felix Fundel provided scripts for MESA. We finally thank Michel Crucifix for his editorial efforts and the two referees (David Archer and Kai Schulz) for their helpful comments.

Edited by: M. Crucifix

\section{References}

Archer, D. E., Eshel, G., Winguth, A., Broecker, W., Pierrehumbert, R., Tobis, M., and Jacob, R.: Atmospheric $p \mathrm{CO}_{2}$ sensitivity to the biological pump in the ocean, Global Biogeochem. Cy., 14, 1219-1230, 2000.

Becquey, S. and Gersonde, R.: Past hydrographic and climatic changes in the Subantarctic Zone of the South Atlantic the Pleistocene record from ODP site 1090, Palaeogeography, Palaeoclimatology, Palaeoecology, 182, 221-239, 2002.

Berger, A., Mélice, J. L., and Loutre, M. F.: On the origin of the 100 -kyr cycles in the astronomical forcing, Paleoceanography, 20, PA4019, doi:10.1029/2005PA001173, 2005.

Bickert, T. and Mackensen, A.: Last Glacial to Holocene Changes in South Atlantic Deep Water Circulation, in: The South Atlantic in the Late Quaternary: Reconstruction of Material Budgets and Current Systems, edited by: Wefer, G., Mulitza, S., and Ratmeyer, V., 671-695, Springer-Verlag, Berlin Heidelberg New York Tokyo, 2004.

Bintanja, R. and van de Wal, R. S. W.: North American ice-sheet dynamics and the onset of the 100,000-year glacial cycles, Nature, 454, 869-872, doi:10.1038/nature07158, 2008.

Bintanja, R., van de Wal, R. S. W., and Oerlemans, J.: Global ice volume variations through the last glacial cycle simulated by a 3-D ice-dynamics model, Quatern. Int., 95-96, 11-23, 2002. 
Bintanja, R., van de Wal, R., and Oerlemans, J.: Modelled atmospheric temperatures and global sea levels over the past million years, Nature, 437, 125-128, doi:10.1038/nature03975, 2005.

Boyle, E. A.: Cadmium and $\delta^{13} \mathrm{C}$ paleochemical ocean distributions during the stage 2 glacial maximum, Annual Review in Earth and Planetary Sciences, 20, 245-287, 1992.

Broecker, W., Lynch-Stieglitz, J., Archer, D., Hofmann, M., MaierReimer, E., Marchal, O., Stocker, T., and Gruber, N.: How strong is the Harvardton-Bear constraint?, Global Biogeochem. Cy., 13, 817-820, 1999.

Brook, E. J., Wolff, E., Dahl-Jensen, D., Fischer, H., and Steig, E. J.: The future of ice coring: International Partnership in Ice Core Sciences (IPICS), PAGES News, 14, 6-9, 2006.

Clark, P. U., Archer, D., Pollard, D., Blum, J. D., Rial, J. A., Brovkin, V., Mix, A. C., Pisias, N. G., and Roy, M.: The Middle Pleistocene Transition: characteristics, mechanisms, and implications for long-term changes in atmospheric $p \mathrm{CO}_{2}$, Quaternary Sci. Rev., 25, 3150-3184, doi:10.1016/j.quascirev.2006.07.008, 2007.

Curry, W. B. and Oppo, D. W.: Glacial water mass geometry and the distribution of $\delta^{13} \mathrm{C}$ of $\sum \mathrm{CO}_{2}$ in the western Atlantic Ocean, Paleoceanography, 20, PA1017, doi:10.1029/2004PA001021, 2005.

Emanuel, W. R., Killough, G. G., Post, W. M., and Shugart, H. H.: Modeling terrestrial ecosystems in the global carbon cycle with shifts in carbon storage capacity by land-use change, Ecology, 65, 970-983, 1984.

EPICA-community-members: Eight glacial cycles from an Antarctic ice core, Nature, 429, 623-628, 2004.

Friedlingstein, P., Cox, P., Betts, R., Bopp, L., von Bloh, W., Brovkin, V., Cadule, P., Doney, S., Eby, Fung, I., Bala, G., John, J., Joos, F., Kato, T., Kawamiya, M., Knorr, W., Lindsay, K., Matthews, H. D., Raddatz, T., Rayner, P., Reick, C., Roeckner, E., Schnitzler, K.-G., Schnur, R., Strassmann, K., Weaver, A. J., Yoshikawa, C., and Zeng, N.: Climate-carbon cycle feedback analysis: results from the $\mathrm{C}^{4} \mathrm{MIP}$ model intercomparison, J. Climate, 19, 3337-3353, 2006.

Gaillardet, J., Dupré, B., Louvat, P., and Allègre, C. J.: Global silicate weathering and $\mathrm{CO}_{2}$ consumption rates deduced from the chemistry of large rivers, Chemical Geol., 159, 3-30, 1999.

Ganachaud, A. and Wunsch, C.: Improved estimates of global ocean circulation, heat transport and mixing from hydrographic data, Nature, 408, 453-457, 2000.

Ghil, M., Allen, M. R., Dettinger, M. D., Ide, K., Kondrashov, D., Mann, M. E., Robertson, A. W., Saunders, A., Tian, Y., Varadi, F., and Yiou, P.: Advanced spectral methods for climatic time series, Rev. Geophys., 40, 1003, doi:10.1029/2000RG000092, 2002.

Hays, J. D., Imbrie, J., and Shackelton, N. J.: Variations in the Earth's Orbit: Pacemaker of the Ice Ages, Science, 194, 11211132,1976

Hellmer, H. H.: Impact of Antarctic ice shelf basal melting on sea ice and deep ocean propoerties, Geophys. Res. Lett., 31, L10307, doi:10.1029/2004GL019506, 2004.

Hönisch, B. and Hemming, N. G.: Surface ocean $\mathrm{pH}$ response to variations in $\mathrm{pCO}_{2}$ through two full glacial cycles, Earth Planet. Sci. Lett., 236, 305-314, doi:10.1016/j.epsl.2005.04.027, 2005.

Hoogakker, B. A. A., Rohling, E. J., Palmer, M. R., Tyrrell, T., and Rothwell, R. G.: Underlying causes for long-term global ocean fluctuations over the last 1.2 Myr, Earth Planet. Sci. Lett., 248, 15-29; doi:10.1016/j.epsl.2006.05.007, 2006.

Huhn, O., Hellmer, H. H., Rhein, M., Rodehacke, C., Roether, W., Schodlok, M. P., and Schröder, M.: Evidence of deep- and bottom-water formation in the western Weddell Sea, Deep-Sea Res. II, 55, 1098-1116, doi:10.1016/j.dsr2.2007.12.015, 2008.

Huybers, P.: Glacial variability over the last two million years: an extended depth-derived agemodel, continuous obliquity pacing, and the Pleistocene progression, Quaternary Sci. Rev., 26, 3755, doi:10.1016/j.quascirev.2006.07.013, 2007.

Imbrie, J., Berger, A., Boyle, E. A., Clemens, S. C., Duffy, A., Howard, W. R., Kukla, G., Kutzbach, J., Martinson, D. G., McIntyre, A., Mix, A. C., Molfino, B., Morley, J. J., Peterson, L. C., Pisias, N. G., Prell, W. L., Raymo, M. E., Shackleton, N. J., and Toggweiler, J. R.: On the structure and origin of major glaciation cycles. 2, The 100,000-year cycle, Paleoceanography, 8, 699735, 1993.

Jin, X., Gruber, N., Dunne, J. P., Sarmiento, J. L., and Armstrong, R. A.: Diagnosing the contribution of phytoplankton functional groups to the production and export of particulate organic carbon, $\mathrm{CaCO}_{3}$, and opal from global nutrient and alkalinity distributions, Global Biogeochem. Cy., 20, GB2015, doi:10.1029/2005GB002532, 2006.

Jouzel, J., Masson-Delmotte, V., Cattani, O., Dreyfus, G., Falourd, S., Hoffmann, G., Minster, B., Nouet, J., Barnola, J. M., Chappellaz, J., Fischer, H., Gallet, J. C., Johnsen, S., Leuenberger, M., Loulergue, L., Luethi, D., Oerter, H., Parrenin, F., Raisbeck, G., Raynaud, D., Schilt, A., Schwander, J., Selmo, E., Souchez, R., Spahni, R., Stauffer, B., Steffensen, J. P., Stenni, B., Stocker, T. F., Tison, J. L., Werner, M., and Wolff, E. W.: Orbital and millennial Antarctic climate variability over the last 800000 years, Science, 317, 793-796, 10.1126/science.1141038, 2007.

Knox, F. and McElroy, M.: Changes in atmospheric $\mathrm{CO}_{2}$ : Influence of the marine biota at high latitude, J. Geophys. Res., 89, 46294637, 1984.

Köhler, P. and Fischer, H.: Simulating changes in the terrestrial biosphere during the last glacial/interglacial transition, Global Planet. Change, 43, 33-55, doi:10.1016/j.gloplacha.2004.02.005, 2004.

Köhler, P. and Fischer, H.: Simulating low frequency changes in atmospheric $\mathrm{CO}_{2}$ during the last 740000 years, Clim. Past, 2, 57-78, 2006, http://www.clim-past.net/2/57/2006/.

Köhler, P., Fischer, H., Munhoven, G., and Zeebe, R. E.: Quantitative interpretation of atmospheric carbon records over the last glacial termination, Global Biogeochem. Cy., 19, GB4020, doi:10.1029/2004GB002345, 2005.

Köhler, P., Fischer, H., Schmitt, J., and Munhoven, G.: On the application and interpretation of Keeling plots in paleo climatic research - Deciphering $\delta^{13} \mathrm{C}$ of atmospheric $\mathrm{CO}_{2}$ measured in ice cores, Biogeosciences, 3, 539-556, 2006a, http://www.biogeosciences.net/3/539/2006/.

Köhler, P., Muscheler, R., and Fischer, H.: A model-based interpretation of low frequency changes in the carbon cycle during the last 120000 years and its implications for the reconstruction of atmospheric $\Delta^{14} \mathrm{C}$, Geochemistry, Geophysics, Geosystems, 7, Q11N06, doi:10.1029/2005GC001228, 2006b.

Kroopnick, P. M.: The distribution of ${ }^{13} \mathrm{C}$ of $\sum \mathrm{CO}_{2}$ in the world oceans, Deep-Sea Res. A., 32, 57-84, 1985. 
Le Quéré, C., Rödenbeck, C., Buitenhuis, E. T., Conway, T. J., Langenfelds, R., Gomez, A., Labuschagne, C., Ramonet, M., Nakazawa, T., Metzl, N., Gillett, N., and Heimann, M.: Saturation of the Southern Ocean $\mathrm{CO}_{2}$ sink due to recent climate change, Science, 316, 1735-1738. doi:10.1126/science.1136188, 2007.

Lisiecki, L. E. and Raymo, M. E.: A Pliocene-Pleistocene stack of 57 globally distributed benthic $\delta^{18} \mathrm{O}$ records, Paleoceanography, 20, PA1003, doi:10.1029/2004PA001071, 2005.

Lisiecki, L. E. and Raymo, M. E.: Plio-Pleistocene climate evoluation: trends and transitions in glacial cycle dynamics, Quaternary Sci. Rev., 26, 56-89; doi:10.1016/j.quascirev.2006.09.005, 2007.

Liu, Z., Cleaveland, L. C., and Herbert, T. D.: Early onset and origin of 100-kyr cycles in Pleistocene tropical SST records, Earth Planet. Sci. Lett., 265, 703-715, doi:10.1016/j.epsl.2007.11.016, 2008.

Loulergue, L., Parrenin, F., Blunier, T., Barnola, J.-M., Spahni, R., Schilt, A., Raisbeck, G., and Chappellaz, J.: New constraints on the gas age-ice age difference along the EPICA ice cores, 050 kyr, Clim. Past, 3, 527-540, 2007, http://www.clim-past.net/3/527/2007/.

Lovenduski, N. S., Gruber, N., Doney, S. C., and Lima, I. D.: Enhanced $\mathrm{CO}_{2}$ outgassing in the Southern Ocean from a positive phase of the Southern Annular Mode, Global Biogeochem. Cy., 21, GB2026, doi:10.1029/2006GB002900, 2007.

Lüthi, D., Floch, M. L., Bereiter, B., Blunier, T., Barnola, J.-M., Siegenthaler, U., Raynaud, D., Jouzel, J., Fischer, H., Kawamura, K., and Stocker, T. F.: High-resolution $\mathrm{CO}_{2}$ concentration record 650 000-800 000 years before present, Nature, 453, 379-382,; doi:10.1038/nature06949, 2008.

Marchitto, T. M., Lynch-Stieglitz, J., and Hemming, S. R.: Deep Pacific $\mathrm{CaCO}_{3}$ compensation and glacial-interglacial atmospheric $\mathrm{CO}_{2}$, Earth Planet. Sci. Lett., 231, 317-336, 2005.

Marinov, I., Follows, M., Gnanadesikan, A., Sarmiento, J. L., and Slater, R. D.: How does ocean biology affect atmospheric $p \mathrm{CO}_{2}$ ? Theory and models, J. Geophys. Res., 113, C07032, doi:10.1029/2007JC004598, 2008.

Martin, J. H.: Glacial-interglacial $\mathrm{CO}_{2}$ change: the iron hypothesis, Paleoceanography, 5, 1-13, 1990.

Maslin, M. A. and Ridgwell, A. J.: Mid-Pleistocene Revolution and the "eccentricity myth", in: Early-Middle Pleistocene transitions: the land-ocean evidence, edited by: Head, M. J. and Gibbard, P. L., vol. 247 of Special Publications, 19-34, Geological Society, London, 2005.

Milankovitch, M.: Kanon der Erdbestrahlung und seine Anwendung auf das Eiszeitenproblem, Special Publications Vol. 132, vol. 33 of Section Mathematics and Natural Sciences, Royal Serbian Acadademy, Belgrad, 1941.

Mix, A. C., Pisias, N. G., Rugh, W., Wilson, J., Morey, A., and Hagelberg, T. K.: Benthic foraminiferal stable isotope record from site 849 (0-5 Ma): local and global climate changes, in: Proceedings of the Ocean Drilling Program, Scientific Results Vol 138, edited by: Pisias, N. G., Mayer, L., Janecek, T., PalmerJulson, A., and van Andel, T., 371-412, College Station, Texas, USA, 1995.

Munhoven, G.: Modelling glacial-interglacial atmospheric $\mathrm{CO}_{2}$ variations: the role of continental weathering, Ph.D. thesis, Université de Liège, Liège, Belgium, 1997.

Munhoven, G.: Glacial-interglacial changes of continental weather- ing: estimates of the related $\mathrm{CO}_{2}$ and $\mathrm{HCO}_{3}^{-}$flux variations and their uncertainties, Global Planet. Change, 33, 155-176, 2002.

Munhoven, G. and François, L. M.: Glacial-interglacial variability of atmospheric $\mathrm{CO}_{2}$ due to changing continental silicate rock weathering: a model study, J. Geophys. Res., 101(D16), 21423 21 437, 1996.

Parekh, P., Joos, F., and Müller, S. A.: The interplay between aeolian iron fluxes and ligands in controlling carbon dioxide fluctuations during Antarctic warm events, Paleoceanography, 23, PA4202, doi:10.1029/2007PA001531, 2008.

Parrenin, F., Barnola, J.-M., Beer, J., Blunier, T., Castellano, E., Chappellaz, J., Dreyfus, G., Fischer, H., Fujita, S., Jouzel, J., Kawamura, K., Lemieux-Dudon, B., Loulergue, L., MassonDelmotte, V., Narcisi, B., Petit, J.-R., Raisbeck, G., Raynaud, D., Ruth, U., Schwander, J., Severi, M., Spahni, R., Steffensen, J. P., Svensson, A., Udisti, R., Waelbroeck, C., and Wolff, E.: The EDC3 chronology for the EPICA Dome C ice core, Clim. Past, 3, 485-497, 2007a, http://www.clim-past.net/3/485/2007/.

Parrenin, F., Loulergue, L., and Wolff, E.: EPICA Dome C Ice Core Timescales EDC3, vol. \# 2007-083 of Data Contribution Series, IGBP PAGES/World Data Center for Paleoclimatology, NOAA/NCDC Paleoclimatology Program, Boulder CO, USA, 2007b.

Petit, J. R., Jouzel, J., Raynaud, D., Barkov, N. I., Barnola, J.-M., Basile, I., Bender, M., Chappellaz, J., Davis, M., Delaygue, G., Delmotte, M., Kotlyakov, V. M., Legrand, M., Lipenkov, V. Y., Lorius, C., Pépin, L., Ritz, C., Saltzman, E., and Stievenard, M.: Climate and atmospheric history of the past 420000 years from the Vostok ice core, Antarctica, Nature, 399, 429-436, 1999.

Pisias, N. G. and Moore Jr., T. C.: The evolution of Pleistocene climate: a time series approach, Earth Planet. Sci. Lett., 52, 450 458, 1981.

Raymo, M. E., Oppo, D. W., and Curry, W.: The mid-Pleistocence climate transition: a deep sea carbon isotopic perspective, Paleoceanography, 12, 546-559, 1997.

Raymo, M. E., Oppo, D. W., Flower, B. P., Hodell, D. A., McManus, J. F., Venz, K. A., Kleiven, K. F., and McIntyre, K.: Stability of North Atlantic water masses in face of pronounced climate variability during the Pleistocene, Paleoceanography, 19, PA2008, doi:10.1029/2003PA000921, 2004.

Raymo, M. E., Lisiecki, L. E., and Nisancioglu, K. H.: PlioPleistocene ice volume, Antarctic climate, and the global $\delta^{18} \mathrm{O}$ record, Science, 313, 492-495; doi:10.1126/science.1123296, 2006.

Sarmiento, J. L. and Toggweiler, J. R.: A new model for the role of the oceans in determining atmospheric $P_{\mathrm{CO}_{2}}$, Nature, 308, 621624, 1984.

Schlitzer, R.: Electronic atlas of WOCE hydrographic and tracer data now available, Eos, 81, 45, 2000.

Schulz, K. G. and Zeebe, R. E.: Pleistocene glacial terminations triggered by synchronous changes in Southern and Northern Hemisphere insolation: The insolation canon hypothesis, Earth Planet. Sci. Lett., 249, 326-336; doi:10.1016/j.eps1.2006.07.004, 2006.

Shackleton, N.: The 100000-year ice-age cycle identified and found to lag temperature, carbon dioxide, and orbital eccentricity, Science, 289, 1897-1902, 2000.

Shackleton, N. J. and Opdyke, N. D.: Oxygen-isotope amd pale- 
omagnetic stratigraphy of Pacific core V28-239: Late Pliocene to latest Pleistocene, in: Investigation of Late Quaternary Paleoceanography, and Paleoclimatology, edited by: Cline, R. M. and Hays, J. D., vol. 145 of Geological Society of America Memoir, 449-464, 1976.

Shackleton, N. J., Berger, A., and Peltier, W. P.: An alternative astronomical calibration of the lower Pleistocene timescale based on OPD site 677, Transactions of the Royal Society of Edinburgh: Earth Sciences, 81, 251-261, 1990.

Siegenthaler, U. and Wenk, T.: Rapid atmospheric $\mathrm{CO}_{2}$ variations and ocean circulation, Nature, 308, 624-626, 1984.

Siegenthaler, U., Stocker, T. F., Monnin, E., Lüthi, D., Schwander, J., Stauffer, B., Raynaud, D., Barnola, J.-M., Fischer, H., Masson-Delmotte, V., and Jouzel, J.: Stable carbon cycle-climate relationship during the late Pleistocene, Science, 310, 13131317, doi:10.1126/science.1120130, 2005.

Stephens, B. B. and Keeling, R. F.: The influence of Antarctic sea ice on glacial-interglacial $\mathrm{CO}_{2}$ variations, Nature, 404, 171-174, 2000.

Swingedouw, D., Fichefet, T., Huybrechts, P., Goosse, H., Driesschaert, E., and Loutre, M.-F.: Antarctic ice-sheet melting provides negative feedbacks on future climate warming, Geophys. Res. Lett., 35, L17705, doi:10.1029/2008GL034410, 2008.

Toggweiler, J. R., 1. Russell, J., and Carson, S. R.: Midlatitude westerlies, atmospheric $\mathrm{CO}_{2}$, and climate change during the ice ages, Paleoceanography, 21, PA2005; doi:10.1029/2005PA001154, 2006.

Tschumi, T., Joos, F., and Parekh, P.: How important are Southern Hemisphere wind changes for low glacial carbon dioxide? A model study, Paleoceanography, 23, PA4208, doi:10.1029/2008PA001592, 2008.

Venz, K. A. and Hodell, D. A.: New evidence for changes in Plio-Pleistocene deep water circulation from Southern Ocean ODP Leg 177 Site 1090, Palaeogeography, Palaeoclimatology, Palaeoecology, 182, 197-220, 2002.
Wang, P., Tian, J., Cheng, X., Liu, C., and Xu, J.: Major Pleistocene stages in a carbon perspective: The South China Sea record and its global comparison, Paleoceanography, 19, PA4005, doi:10.1029/2003PA000991, 2004.

Wang, P. X.: Feeling the Earth's pulse from global monsoon records, Geophys. Res. A., 9, 05820; SRef-ID: 16077962/gra/EGU2007-A-05820, 2007.

Watson, A. J. and Naveira-Garabato, A. C.: The role of Southern Ocean mixing and upwelling in glacial-interglacial atmospheric $\mathrm{CO}_{2}$ change, Tellus B, 58B, 73-87, 2006.

Wolff, E. W., Chappellaz, J. A., Fischer, H., Krull, C., Miller, H., Stocker, T., and Watson, A. J.: The EPICA challenge to the Earth System Modeling Community, EOS, 85, 363, 2004.

Wolff, E. W., Kull, C., Chappellaz, J., Fischer, H., Miller, H., Stocker, T. F., Watson, A. J., Flower, B., Joos, F., Köhler, P., Matsumoto, K., Monnin, E., Mudelsee, M., Paillard, D., and Shackleton, N.: Modeling past atmospheric $\mathrm{CO}_{2}$ : results of a challenge, EOS, 86(38), p. 341, p. 345, 2005.

Wolff, E. W., Fischer, H., Fundel, F., Ruth, U., Twarloh, B., Littot, G. C., Mulvaney, R., Röthlisberger, R., de Angelis, M., Boutron, C. F., Hansson, M., Jonsell, U., Hutterli, M., Lambert, F., Kaufmann, P., Stauffer, B., Stocker, T. F., Steffensen, J. P., Bigler, M., Siggaard-Andersen, M. L., Udisti, R., Becagli, S., Castellano, E., Severi, M., Wagenbach, D., Barbante, C., Gabrielli, P., and Gaspari, V.: Southern Ocean sea-ice extent, productivity and iron fluxes over the past eight glacial cycles, Nature, 440, 491-496, doi:10.1038/nature04614, 2006.

Zeebe, R. E., and Caldeira, K.: Close mass balance of long-term carbon fluxes from ice-core $\mathrm{CO}_{2}$ and ocean chemistry records, Nature Geoscience, 1, 312-315; doi:10.1038/ngeo185, 2008. 